\title{
Directory of Residency and Fellowship Programs in Women's Health
}

\section{Mission Statement}

The mission of the Association of Academic Women's Health Programs (AAWHP) is to improve the health of women through leadership in research, education clinical models, and community partnerships. This mission is carried out through networking, leadership and mentoring collaborative projects, lobbying and advocacy, political and social commentary, education of policy-makers, partnership with national organizations, and creation of interdisciplinary innovative models.

\section{May 2015}




\section{Contents}

Overview

\section{Residencies in Interdisciplinary Women's Health}

Brown University Warren Alpert Medical School (RI) 415

Massachusetts General Hospital/Harvard University School of Medicine (MA) 416

Northwestern University, Feinberg School of Medicine (IL) 417

Stony Brook University Medical Center (NY) 418

University of Alabama Hospital in Birmingham (AL) 419

University of Kentucky (KY) $\quad 420$

University of Pittsburgh Medical Center/University of Pittsburgh School 421 of Medicine (PA)

Virginia Commonwealth University Medical Center (VA) 422

\section{Fellowships in Women's Health}

Bixby Center for Global Reproductive Health, San Francisco (CA) 424

Boston University School of Medicine/VA Boston Healthcare System (MA) 425

Brigham and Women's Hospital/Harvard Medical School (MA) 427

Brigham and Women's Healthcare, Harvard Medical School (MA) 428

Brown University Warren Alpert Medical/Consultative \& Obstetric Medicine 429

Brown University Warren Alpert Medical School (RI)/Emergency Medicine 430

Case Western Reserve University/University Hospitals Case Medical Center (OH) 432

Cedars-Sinai Medical Center (CA) 433

Cleveland Clinic Foundation (OH) 434

Columbia University Medical Center (NY) 436

East Carolina University Brody School of Medicine (NC) 437

Edward Hines Jr. VA Hospital and Loyola University Stritch School of Medicine (IL) 438

MacNeal Hospital (IL) $\quad 439$

Mayo Clinic College of Medicine (MN) 440

Medical College of Wisconsin/Milwaukee Veterans Affairs Medical Center (WI) 441

Portland Veterans Affairs Medical Center (OR)/Oregon Health and Science University 442

San Francisco VA Advanced Fellowship in Women's Health 443

University of California, Los Angeles/VA Greater Los Angeles Healthcare System (CA) 444

University of California at San Francisco/Women's Health Clinical Research 445 Center (CA)

University of Illinois at Chicago College of Medicine (IL) 446

University of Medicine and Dentistry of New Jersey/Robert Wood Johnson Medical 447 School (NJ)

University of Michigan School of Medicine (MI) 448

University of Pittsburgh School of Medicine/Pittsburgh Veterans Affairs Medical 449 Center (PA)

University of Wisconsin School of Medicine/Veterans Affairs Medical Center (WI) 450

VA Connecticut Healthcare System/Yale School of Medicine (CT) 451

VA San Diego Healthcare System (VASDHS)/University of California San Diego (UCSD) 453 


\section{Overview}

$\mathbf{I}$

n support of interdisciplinary Women's Health training programs, the Journal of Women's Health is pleased to publish the Directory of Interdisciplinary Women's Health Residencies and Fellowships. The Directory was initially developed under the direction of Dr. Saralyn Mark from a national survey of 1,355 hospitals conducted in September 1995. Information from the Association of American Medical Colleges, the American Association of Colleges of Osteopathic Medicine, and the American Hospital Association was used to identify institutions approved for Women's Health residency and fellowship programs. The following are criteria for inclusion of residency and fellowship programs in the Directory:

1. The program should be interdisciplinary in nature, crossing traditional boundaries, in order to comprehensively focus on a wide range of Women's Health concerns and issues, including, but not limited to, mental health, aging, reproductive health, urogynecology, gender differences in disease presentation and treatment, bone health, heart health, and breast health.

2. The program should have a separate application process with its own director within an academic medical center or accredited graduate medical education program.

3. To qualify as a residency program in Women's Health, the program should offer a specialized curriculum in Women's Health in addition to the required activities of a traditional residency track.

The Directory was previously published by the Office on Women's Health in the Department of Health and Human Services in 1995, and has been updated annually since then. In 2004, the Association of Academic Women's Health Programs (AAWHP) assumed responsibility for maintaining and updating the Directory. AAWHP is a national non-profit organization whose members include Women's Health educators, researchers, and program directors at academic institutions. Its mission is to improve the health of women through leadership in research, education, clinical models, and community partnerships and to accelerate translation of research into clinical practice. This mission is carried out through networking, leadership and mentoring, collaborative projects, advocacy, political and social commentary, education of policymakers, partnership with national organizations, and creation of innovative models, including Women's Health fellowships and residency programs.

The interdisciplinary programs included in this Directory model the integration of educational experiences across departments, such that future physicians can be trained to more effectively provide comprehensive care for women. In addition, Women's Health fellowships are a breeding ground for new researchers in this field. The publication of the Directory will help to disseminate program information and foster awareness of these programs, and will hopefully expand and enhance graduate medical education in the area of Women's Health.

If any training program meets inclusion criteria and has been unintentionally omitted from this Directory, AAWHP would like to be promptly notified. The Directory will continue to be updated annually as new curricula develop. For questions regarding program inclusion or for information regarding AAWHP, please contact Millie Becker at jwh@vcu.edu. 


\section{Residencies in Interdisciplinary Women's Health}




\section{Institution(s) \\ Brown University Warren Alpert Medical School \\ Program Type: General Internal Medicine Women's Health Track}

Date Established: 2006

Number of Positions: 2 per year

Sponsored by: Department of Internal Medicine

Contact(s):

Director: Kelly A. McGarry, MD

Contact: Annmarie Pedro

Telephone: 401-444-5953

E-mail: kmcgarry@lifespan.org

\& apedro1@lifespan.org

Website: www.brownmedicine.org/education/ gim_fellow.asp

\section{Eligibility Requirements}

Applicants must match into the General Internal Medicine/ Primary Care Program.

\section{Application Process}

Residents in the Women's Health Track first match into the General Internal Medicine Program, then declare their desire to participate in the track.

\section{Required Activities}

- Clinical experiences are organized throughout the first 6 months of ambulatory block over the first two years of residency.

- Research generally begins in the second year of residency and will culminate in a publication and/or national presentation.

- Advising/Mentoring takes place quarterly with the clinical and research advisors.

- Residents will also have a half-day per week second continuity site in women's health beginning in their $2^{\text {nd }}$ year and continuing through residency training.

There is also a required teaching activity. In their $3^{\text {rd }}$ year of residency, residents will teach $1^{\text {st }}$ year GIM residents in Ambulatory Block. They will develop a seminar in an area of women's health in which they are interested.

\section{Elective Activities}

Numerous elective experiences exist. A month-long women's health elective is suggested for all track participants. This includes clinical experiences in the GYN Clinic, Breast Surgery Clinic, Mammography, Urogynecology, and Psychiatry. Residents may also choose to observe in Colposcopy Clinic.

\section{Special Degree(s)/Certificate(s) Offered}

There is no special degree awarded, although at graduation, they will receive a certificate acknowledging their participation.

\section{Goals of the Program}

Our goal is to foster the development of a physician who excels both from a clinical as well as academic perspective in women's health.

\section{Other Program Features}

Our program focuses on both the clinical and academic aspects of Women's Health. Clinically, our focus is on women's health from an internal medicine perspective. We have clinical experiences at women's health internal medicine practices and at our women's prison. While these dominate the clinical experiences, we also have gynecologic experiences in women's health. Academically, our research advisor guides the resident through a project with the goal of presenting at a national meeting.

\section{Reasons for Initiating Program}

Brown University Medical School has always excelled clinically and academically in women's health. We decided to seize upon those strengths and create an organized curriculum for applicants interested in a clinical or academic career in women's health. There remains a need for physicians who specialize in the care of women. 
Institution(s)

Massachusetts General Hospital/Harvard

University School of Medicine (MA)

Program Type: Women's Health Track of the Primary Care Residency Program

Date Established: July 1995

Number of Positions: 2 per year

Duration of Program: 3 years

Sponsored by:

Department of Medicine

Co-Sponsoring Institution(s)/Department(s):

Department of Obstetrics and Gynecology

Contact(s):

Karen O'Brien, MD

Director of Women's Health Focus in Primary Care

Medicine Residency Program

E-mail: kaobrien@ partners.org

Karen Carlson, MD

Director of Women's Health Associates

Massachusetts General Hospital

Yawkey 4B, 55 Fruit Street

Boston, MA 02114

Telephone: (617) 724-6700

Fax: (617) 724-6725

\section{Eligibility Requirement(s)}

A medical degree is required.

\section{Required Activities}

In addition to inpatient rotations in Internal Medicine, residents are required to participate for three to four months each year in a multidisciplinary primary care practice for women. This experience provides ambulatory subspecialty training in Gynecology, Orthopedics, Dermatology, and breast disease.

\section{Elective Activities}

Six- to eight-week electives in Endocrinology, Infectious Disease, Arthritis, and Obstetrics and Gynecology are offered in the third year of residency.

\section{Special Degree(s)/Certificate(s) Offered}

Residents are board eligible in Internal Medicine.

\section{Goals of the Program}

To provide comprehensive training in ambulatory General Medicine, Gynecology, and other specialties relevant to primary care of women in the context of an inpatient Internal Medicine residency.

\section{Other Program Features}

Formal mentorship programs and mini-courses in clinical and nonclinical topics with specified goals and objectives are available.

\section{Reason for Initiating Program}

The program was created to expand opportunities within existing primary care residency training to focus on the special needs of women in an integrated, multidisciplinary clinical practice site. 


\section{Institution(s) \\ Northwestern University, Feinberg School of Medicine}

Program Type: General Internal Medicine-Women's Health Residency Track

Date Established: July 2002

Duration of Program: 3 years

Sponsored by:

Department of Internal Medicine

Contact(s):

Aashish Didwania, MD

Director, Internal Medicine Residency Training Program

Northwestern University Feinberg School of Medicine

Department of Medicine

251 East Huron Street

Galter Pavilion, Suite 3-150

Chicago, IL 60611

Telephone: 312-926-4227

Diane B. Wayne, MD

Vice Chair of Education

Northwestern University Feinberg School of Medicine

Department of Medicine

251 East Huron Street

Galter Pavilion, Suite 3-150

Chicago, IL 60611

Telephone: 312-926-4227

E-mail: dwayne@northwestern.edu

Website: http://www.medicine.northwestern.edu/ residency/curriculum/womens-health-track

\section{Eligibility Requirements}

Acceptance to Northwestern Internal Medicine training program is required.

\section{Application Process}

There is not a separate match for the women's health track. Those interested in the program should apply to the categorical internal medicine program through the Electronic Residency Application Service (ERAS). The program is listed as Northwestern/McGaw/NMH/VA-IL, the program number is $2247140 \mathrm{CO}$ for Categorical Medicine. Anyone matching in the categorical internal medicine program is eligible to participate in the track.

\section{Required Activities}

Residents will be required to: 1 . Attend the women's health conferences and quarterly journal club; 2 . Rotate through the multidisciplinary Women's Health Block one month each year as a senior resident. This block includes, but is not limited to, clinic experiences in gynecology, osteoporosis, urogynecology, breast disease/breast imaging, endocrinology/PCOS, weight management, cardiology, dermatology; 3 . Complete a two-month research block in an area of women's health; 4. Participate in continuity clinic supervised by women's health preceptors (one half day a week year 1, two half days a week years 2 and 3 ).

\section{Elective Activities}

Residents may elect to do 1-2 months of gynecology, additional Women's Health Block months, or other electives months designed to meet their individual interests.

\section{Special Degree(s)/Certificate(s) Offered}

A certificate in women's health will be offered at the end of the residency program.

\section{Goals of the Program}

The track was established to provide research opportunities and additional clinical experience in the women's health and gender-based medicine for internal medicine residents. Residents in this track will receive this education in conjunction with the usual training in the categorical program. Upon completion of the curriculum, graduates will be well prepared for pursuing academic careers in women's health, including further specialty training.

\section{Other Program Features}

Northwestern Feinberg School of Medicine has been awarded NIH funding for the Building Interdisciplinary Research Careers in Women's Health program (BIRCWH), a career development grant which supports young faculty focused on careers in women's health research. Women's health residents will be able to participate in many of the conferences offered to the BIRCWH awardees including a core course in women's health and special research seminars.

\section{Reason for Initiating Program}

The program was initiated to expand the clinical and research opportunities for internal medicine residents interested in women's health. 
Institution(s)

Stony Brook University Medical Center (NY)

Program Type: Primary Care Internal Medicine Residency

Date Established: 1998

Number of Positions: 6 per year

Sponsored by:

Department of Internal Medicine

Contact(s):

Rachel Wong, MD

Director of Primary Care Program

Stony Brook University Medical Center

HSC T-16-080

Stony Brook, NY 11794

Telephone: 631-444-2065

Fax: 631-444-2493

E-mail: Rachel.Wong@stonybrookmedicine.edu

Website: www.stonybrookmedicalcenter.org= medicine $=$ residency $=$ primarycare_track.cfm

\section{Eligibility Requirements}

A medical degree is required.

\section{Application Process}

Interested candidates should apply through the Primary Care Residency Program.

\section{Required Activities}

The following clinical activities are offered: 1) Weekly continuity clinic in the Veterans' Affairs Women's Health Clinic, 2) One month rotation in women's health including clinical training in women's primary care clinic, ob/gyn clinic, sexually transmitted disease clinic, breast care center, osteoporosis center, women's cardiology clinic, urogynecology clinic, 3) attendance at didactic sessions and journal clubs discussing women's health issues.

\section{Elective Activities}

Opportunities to work one-on-one with women's health primary care providers in private practice settings, research opportunities in women's health preventive medicine.

\section{Special Degree(s)/Certificate(s) Offered}

Special degrees and certificates are not offered.

\section{Goals of the Program}

To develop expertise in preventive and primary health care of women.

\section{Other Program Features}

The primary care residents are fully integrated into the residency training program. The unique training of the primary care residents in the women's health track enables them to become experts among their peers in the practice of primary care for women.

\section{Reason for Initiating Program}

Recognition of the unique aspects of care essential to provide comprehensive and excellent primary care to women. 


\section{Institution(s)}

University of Alabama Hospital in Birmingham (AL)

Program Type: Residency in Women's Health

Date Established: July 1999

Number of Positions: 2 per year

Duration of Program: 3 years

Sponsored by:

Department of Internal Medicine

Co-Sponsoring Institution(s)/Department(s): Department of Gynecology

Contact(s):

Erin Contratto, MD

Director, Women's Health Track

1720 2nd Avenue South

BDB 327

Birmingham, AL 35294-3407

Telephone: (205) 975-3909

Fax: (205) 975-7797

E-mail: econtratto@uab.edu

Website: http://www.uab.edu/medicine/imresidency/ program/tracks/womens-health-track/

\section{Eligibility Requirement(s)}

Acceptance to University of Alabama Hospital in Birmingham, Internal Medicine Residency training program is required.

\section{Required Activities}

Residents will be required to complete the following activities: 1) attend a Continuity Women's Clinic every other week, 2) participate in 3-4 month long ambulatory rotations with a $50 \%$ focus in women's health, 3) participate in women's health conferences and journal clubs, and 4) complete all requirements of the UAB Internal Medicine residency program.

\section{Elective Activities}

Elective activities include women's health research projects and attendance of regional/national meetings.

\section{Special Degree(s)/Certificate(s) Offered}

Residents are board eligible in Internal Medicine.

\section{Goals of the Program}

To provide training in primary care with an additional focus in women's health. Residents receive gender specific training to allow provision of comprehensive healthcare to women, in addition to a solid foundation in all traditional aspects of internal medicine.

\section{Other Program Features}

Participation in Gynecology Clinic, Breast Clinic, Osteoporosis Clinic, High Risk OB Clinic, Endocrine Clinic, STD Clinic, Continence Clinic, and other ambulatory rotations. Curriculum is very flexible and tailored to the interest and requests of each individual resident.

\section{Reason for Initiating Program}

Our Women's Health Residency was developed to provide interested residents with additional expertise in the area of women's health. 


\section{Institution(s)}

University of Kentucky (KY)

Program Type: Residency in Women's Health

Date Established: 1999

Number of Positions: 4-6 per year

Duration of Program: 2-3 years

Sponsored by:

Department of Internal Medicine

Co-Sponsoring Institution(s)/Department(s): School of Nursing

Contact(s):

Deidre Beashear, MD

Director, WH Residency Training Program

Jackie Carey, MD

Co-Director, WH Residency Training Program

Center for the Advancement of Women's Health

Room J-503 Kentucky Clinic

740 South Limestone Street

Lexington, KY 40536-0284

Telephone: (859) 323-4939

Fax: (859) 257-8258

E-mail: dbesh2@email.uky.edu; jecare1@email.uky.edu

Website: www.mc.uky.edu/primarycare

residency/index.asp?page $=$ include /

welcome.asp

\section{Eligibility Requirement(s)}

An applicant must be an Internal Medicine resident in good standing, with an interest in women's health.

\section{Required Activities}

Residents must treat patients in the Women's Health Clinic under the direction of a women's health preceptor one afternoon per week for 2-3 years, attend monthly women's health grand rounds, and participate in a weekly evidencebased women's health pre-clinic conference.

\section{Elective Activities}

Elective activities include an ambulatory GYN elective, female urology, comprehensive headache clinic, and a research elective.

\section{Special Degree(s)/Certificate(s) Offered}

A certificate as resident in women's health is available.

\section{Goals of the Program}

To provide residents with solid internal medicine training, with additional expertise in women's health. This expertise is evidence-based and is obtained through clinical experience.

\section{Other Program Features}

Multi-disciplinary clinic designed by women, for women, which includes primary care providers, adult and adolescent gynecology, rheumatology, gastroenterology, neurology and urogynecology. The clinic has a research and educational program including the Kentucky Women's Health Registry designed to understand the epidemiology of symptoms and diseases as well as to increase participation of women in clinical trials.

\section{Reason for Initiating Program}

This Women's Health track was started as part of an effort to provide specific education and clinical skills in women's health to internal medicine residents. Past surveys of both faculty and residents at our institution revealed a deficit in women's health knowledge, and a deficit of women's health topics in the traditional curriculum. Additionally, this women's health track is one facet of an expanding women's health curriculum throughout the entire medical center, as our University is the recipient of a multidisciplinary FIPSE (Fund for Improving Post-Secondary Education) grant to integrate women's health into the curriculum of health professionals. 
Institution(s)

University of Pittsburgh Medical Center/ University of Pittsburgh School of Medicine/ VA Pittsburgh Health Care System

Program Type: Residency Track in Women's Health

Date Established: June 1983

Number of Positions: 4 per year

Duration of Program: 3 years

Sponsored by:

Department of Medicine

Co-sponsoring Institutions/Departments:

Departments of Obstetrics and Gynecology, Psychiatry and Pediatrics

Contact:

Melissa McNeil, MD, MPH

Professor of Medicine and Obstetrics, Gynecology and Reproductive Sciences

Division of General Internal Medicine

UPMC Montefiore, Suite W933

200 Lothrop Street

Pittsburgh, PA 15213

Telephone: 412-692-4821

Fax: 412-692-4825

E-mail: mcneilma@upmc.edu

Website: http://residency.dom.pitt.edu/

Program_Overview/tracks/womens_health.html

\section{Eligibility Requirement(s)}

A medical degree is required.

\section{Required Activities}

The Women's Health Track combines areas of obstetrics, gynecology, psychiatry, and adolescent medicine into a multidisciplinary experience that prepares residents to provide more comprehensive gender specific primary care to women patients. Topic areas covered in depth include: contraceptive management, menstrual dysfunction assessment, postmenopausal hormone replacement, cervical and breast cancer screening, medical management of the pregnant patient. Traditional internal medicine domains such as cardiovascular disease, lipid disorders, osteoporosis, autoimmune diseases are presented with special attention to the gender based differences in diagnosis and management. Special attention is also given to the management of psychosocial issues with a unique burden in women such as domestic violence, sexual violence, eating disorders, depression, and anxiety.

These educational goals are accomplished in several ways. Women's Health Track residents have specially designed primary care clinics staffed by core faculty in the Women's Health Program where gender issues are routinely managed. In addition, there are specialized block rotations over the three years which cover routine and acute gynecologic care, urogynecology, reproductive endocrinology, adolescent medicine, the women's heart program, behavioral medicine, and the medical complications of pregnancy. Special didactics such as a monthly journal club dedicated to the discussion of women's health topics are also included.

\section{Elective Activities}

Elective opportunities in addition to the required core rotations abound. We are affiliated with both Magee Women's Hospital and the VA Pittsburgh National Center of Excellence in Women's Health. Special rotations include: high risk breast clinic, cardiovascular disease in women, thyroid disorders, management of the midlife woman to name just a few.

\section{Special Degree(s)/Certificate(s) Offered}

Residents are board certified in Internal Medicine but receive a certificate of completion of the Women's Health Residency Track.

\section{Goals of the Program}

The Women's Health Track is a specialized course of instruction designed to provide comprehensive internal medicine training with an added emphasis in managing problems different in, unique to, or more common in women. It is appropriate both for trainees envisioning a career in primary care as well as those planning for a subspecialty career with a focus on gender issues in their specialty.

\section{Other Program Features}

Weekly interdisciplinary women's health seminar series that allows for in-depth discussion of specific issues related to women's health.

\section{Reason for Initiating the Program}

To provide a unique training opportunity for both primary care and subspecialty physicians to learn about comprehensive, gender specific care for women. 


\section{Institution(s) \\ Virginia Commonwealth University Medical Center (VA)}

Program Type: Residency in Women's Health

Date Established: June 1997

Number of Positions: 4-5 per year

Duration of Program: 3 years

Sponsored by:

Department of Medicine

Contact(s):

Stephanie Call, MD, MSPH

Program Director

Internal Medicine Residency

Maia LaVallee, MS

Virginia Commonwealth University

School of Medicine

P.O. Box 980509

Richmond, VA 23298-0509

Telephone: (804) 828-9726

Fax: (804) 828-4926

E-mail: imea@vcu.edu

Website: www.womenshealthtrack.vcu.edu

\section{Eligibility Requirement(s)}

A medical degree is required.

\section{Required Activities}

In addition to the required rotations and conferences in the Internal Medicine program, residents participate in outpatient clinics in Gynecology throughout the year. Other required activities include two months in the multidisciplinary Women's Health Center and a one-month multidisciplinary rotation in Breast Health. Additionally, throughout the year there are seminars and small discussions on primary care and women's health topics in conjunction with half-day continuity clinics.

\section{Elective Activities}

Residents may elect further experience, schedule permitting.

\section{Special Degree(s)/Certificate(s) Offered}

Residents are board eligible in Internal Medicine.

\section{Goals of the Program}

To provide broad-based clinical training in Internal Medicine with a central focus on women's health promotion, disease prevention and biopsychosocial issues; to increase awareness among health care professionals regarding issues in women's health, and to promote leadership, research and education in women's health.

\section{Other Program Features}

Residents are exposed to a wide variety of learning opportunities, clinicians, and patients. In Bone Clinic, the use of bone densitometry and osteoporosis management are included during the Women's Health blocks. Other clinic experiences during this block include Urogynecology, Gyn Oncology, and Endocrine. Additionally, residents may attend the Fan Free Clinic, an outreach clinic, and Women's Health Physical Therapy, which exposes residents to therapy for urinary incontinence and constipation. The Breast Health month is a multidisciplinary rotation in medical oncology, surgical oncology, radiation oncology, mammography, pathology, and lactation consultation. A Women's Health Journal Club meets monthly to discuss issues relevant to women's health. There is a strong mentoring component, utilizing expert women faculty as discussants and lecturers.

\section{Reason for Initiating Program}

To provide comprehensive multidisciplinary training for Internal Medicine residents with interest in the area of Women's Health, whether they are planning a career in General Medicine or subspecialty training. 


\section{Fellowships in Women's Health}


Institution(s)

Bixby Center for Global Reproductive Health at the University of California, San Francisco

Sites:

Programs based in Obstetrics and Gynecology: Boston University Columbia University

Emory University

Harvard Medical School

Johns Hopkins University

Mount Sinai School of Medicine

NewYork University

Northwestern University

Oregon Health and Science University

Stanford University

University of California, Los Angeles

University of California, San Francisco

University of Chicago

University of Colorado

University of Illinois, Chicago

University of Michigan

University of New Mexico

University of North Carolina

University of Pennsylvania

University of Pittsburgh

University of Southern California

University of Utah

University of Washington

Washington Hospital Center

Washington University

Programs based in Family Medicine:

Albert Einstein College of Medicine

Program Type: Fellowship in Family Planning

Date Established: 1991

Number of Positions: 1 fellow per site per year

Duration of Program: 2 years

Sponsoring Institution: Bixby Center for Global Reproductive Health

$\operatorname{Contact}(\mathbf{s})$ :

Megan Grimm, MPH

Fellowship in Family Planning National Office

Telephone: (415) 502-8462

E-mail: info@familyplanningfellowship.org

Website: http://familyplanningfellowship.org/

\section{Eligibilty Requirements}

A fellow must have satisfactorily completed a residency in obstetrics and gynecology accredited by the American Council for Graduate Medical Education (ACGME) or the Council of the Royal College of Physicians and Surgeons of Canada (CRCPSC).

\section{Required Activities}

Clinical experience sufficient to develop competency in contraception and abortion care according to the requirements outlined in the General Requirements and Guide to Learning, completion and presentation of a publishable research project, participation in a global health placement, an completion of a masters degree in public health or science.

\section{Elective Activities}

Rotations with the Population Council, World Health Organization, American Congress of Obstetricians and Gynecologists, and similar agencies and NGOs are available.

\section{Special Certificates/Degrees Offered}

Masters Degree in Public Health or Masters Degree in Science.

\section{Goals of the Program}

The objective of the program is to develop specialists focused on research, teaching and clinical practice in contraception and abortion. Working with respected and innovative leaders in the field, fellows receive training in clinical and epidemiologic research, develop clinical and teaching skills, have opportunities to work internationally and connect to a rapidly expanding network of family planning experts.

\section{Reason for Initiating the Program}

To enhance the academic and operational status of family planning and abortion services and to prepare specialists who can provide family planning leadership through academic or programmatic positions while also providing excellent clinical care. 
Institution(s)

Boston University School of Medicine

Program Type: Women's Health Fellowship, a concentration within the BU General Internal/ Family Medicine Fellowship program

Date Established: 1994

Number of Positions: 1-2 per year

Duration of Program: 2 years

Sponsored by:

Department of Medicine

Co-Sponsoring Institution(s)/Department(s):

VA Boston Healthcare System,

Boston Medical Center

\section{Contact(s):}

Megan R. Gerber, MD, MPH

Director, Advanced Fellowship in Women's Health

VA Boston Healthcare System

150 S. Huntington Avenue (PC11/WHC)

Jamaica Plain, MA 02130

Telephone: $857-364-5932$

Fax: 857-364-6686

E-mail: Megan.gerber@va.gov

Tracy Battaglia, MD, MPH

Director, Women's Health Unit, BU School of Medicine

Fellowship Site Director, Boston University

Crosstown Center, 1st Floor

801 Massachusetts Avenue

Boston, MA 02118

Telephone: (617) 638-8036

Fax: (617) 638-8096

E-mail: Tracy.Battaglia@bmc.org

Amy Street, PhD

Co-director, Fellowship in Health Issues

of Women Veterans

Director, Advanced Women's Health

Fellowship Psychology Track

National Center for PTSD (116B-3)

VA Boston Healthcare System

150 South Huntington Avenue

Jamaica Plain MA, 02130

Telephone: 857-364-5998

Fax: 857-364-4515

E-mail: Amy.street@va.gov

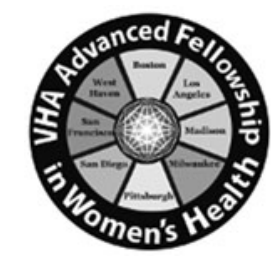

Medical Track:

Eligibility Requirements

Eligible physicians must have graduated from an Accreditation Council for Graduate Medical Education (ACGME) accredited residency; be board certified or board eligible in internal medicine (or one of its subspecialties), or family practice. An active, unrestricted U.S. medical license is required.

International medical graduates must also have a current visa to participate in the program and an Educational Commission for Foreign Medical Graduates (ECFMG) certificate that is valid indefinitely. Applicants with a J-1 visa must have current ECFMG sponsorship to participate in the program.

\section{Required Activities}

The VA Health Issues of Women Veterans Fellowship in collaboration with the Boston University (BU) General Internal Medicine Fellowship Program provides two years of post residency, post-doctoral research, education, and clinical learning opportunities to eligible physicians. The program began in 1994 and graduates have gone on to successful careers in academic women's health as researchers and educators. The program is based on a comprehensive model of women's health with a focus on addressing health disparities in women. Fellows spend approximately 75 percent of their time in project work and 25 percent in clinical care at selected VA sites. Graduates are expected to be role models in leading, developing, conducting, and evaluating innovative research as well as excelling at medical education and clinical care in women's health settings. Fellows complete a Master's program (Health Services, Epidemiology or Education) and take course work that helps facilitate their career objectives.

Career development seminars at BU in clinical research, medical education, administration and management are core elements of the fellowship. A minimum of two scholarly projects are required during the fellowship, at least one must focus on the health of women veterans. Current active research topics include trauma exposure and health outcomes, cancer prevention, and gender disparities.

\section{Special Certificate(s)/Degree(s) Offered}

Master's Degree in Science (Health Services, Epidemiology) or Education at the Boston University School of Public Health or School of Education. 


\section{Psychology Track}

\section{Postdoctoral Research Track in Women's Mental Health:}

The primary objective of this training program is to produce clinical researchers in women's mental health, with a focus on the scientific study of stress, trauma, and posttraumatic stress disorder (PTSD). The fellowship represents one track within the Advanced Fellowship in Women's Health, is closely affiliated with the BU School of Medicine and is housed within the Women's Health Sciences Division of the National Center for PTSD (WHSD/NCPTSD).

Resources include didactic training, technical support personnel, psychophysiology and cognitive research laboratories, advanced computing facilities, and a broad range of professional expertise. Fellows may participate in ongoing research, initiate independent research projects, conduct secondary analyses on existing data sets, prepare applications to federal and other funding agencies for research support, and provide direct clinical services to patients under clinical supervision. Fellowship graduates should have the potential to be role models in leading, developing, conducting, and evaluating innovative research, education, and clinical care in health issues pertaining to women veterans.

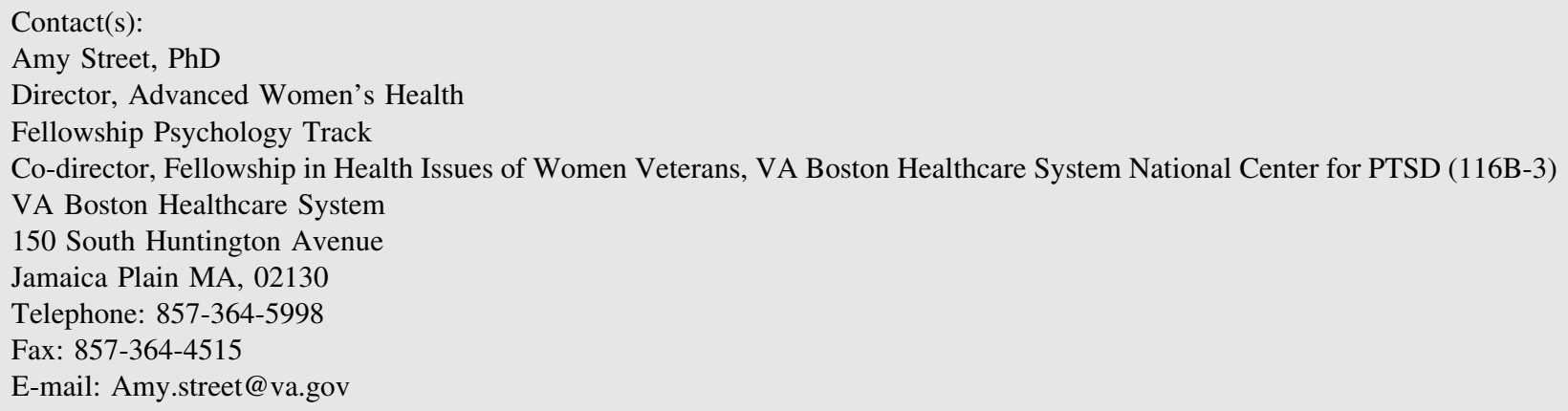


Institution

Brigham and Women's Hospital

Program Type: Global Women's Health Fellowship

Date Established: 2007

Number of Positions: 1-3 per year

Duration: 2 years

Sponsoring Institution: Connors Center for Women's Health and Gender Biology/Department of Medicine, Brigham and Women's Hospital

Co-Sponsoring Institutions/Department: Harvard Humanitarian Initiative, Harvard Global Health Institute and Harvard School of Public Health

Contact(s):

Stephanie Kayden, MD, MPH

Fellowship Director

Connors Center for Women's Health

Brigham and Women's Hospital

75 Francis Street

Boston, MA 02115

Jaclyn Chai, MPH

Administrative Director,

Global Women's Health Programs

Connors Center for Women's Health

1620 Tremont Street, $3^{\text {rd }}$ Floor

Boston, MA 02120

Telephone: (617) 525-6766

Fax: (617) 525-7746

E-mail: jchai1@partners.org

\section{Eligibility Requirement(s)}

Board eligible/certified in their trained specialty is required.

\section{Required Activities}

Fellows will be expected to divide their time between global research, Harvard School of Public Health, or other classes, and clinical work. The curriculum is tailored to fellows' individual interests and is divided into six areas: (1) Understanding the landscape of Global Women's Health; (2) Women's Health and Human Rights; (3) Key Issues in Global Women's Health; (4) Methods of Global Health Research; (5) Monitoring and Evaluation of Global Women's Health Programs; and (6) Leadership Skills. These are achieved through a combination of in-class learning, educational seminars, journal clubs, research retreats, intense mentorship and various other academic activities.

\section{Elective Activities}

The program supports training related to each fellows' individual research interests, as well, offers the option of participating in the Humanitarian Studies Initiative Training Program.

\section{Special Certificates/Degrees Offered}

Masters Degree in Public Health

\section{Goals of the Program}

Successful Global Women's Health fellows will:

(1) Be on the path towards a successful career dedicated to furthering the health and well-being of women globally;

(2) Be able to conduct clinical and field research based on solid quantitative and analytic research skills;

(3) Obtain fundamental knowledge and understanding of global health issues that uniquely affect the health of women within the context of specific social, cultural, and political environments;

(4) Develop administrative leadership skills through understanding how to assess, build, implement, monitor, and evaluate Global Women's Health programs; and,

(5) Understand the particularly vulnerable role of women in humanitarian crises, war, conflict and disasters.

\section{Reason for Initiating the Program}

Brigham \& Women's Global Women's Health Fellowship seeks to train physicians for successful careers dedicated to furthering the health and well-being of women globally through innovative, meaningful and wide-reaching research. This two-year training program prepares physicians who want to pursue an academic career path in Global Women's Health research, understand how best to serve specific populations of women, and contribute to the knowledge-base of the field of Global Women's Health.

URL: http://www.brighamandwomens.org/gwh 
Institution(s)

Brigham and Women's Healthcare,

Harvard Medical School

Program Type: Fellowship in Women's Mental Health

Date Established: 2006

Number of Positions: 1 per year

Duration of Program: 1 year

Sponsored by: Department of Psychiatry

Contact(s)

Hadine Joffe, MD, MSc

Director, Women's Mental Health Division

Department of Psychiatry

Brigham and Women's Hospital

75 Francis St.

Boston MA 02115

Telephone: 617-732-4906

FAX: 617-264-6326

E-mail: hjoffe@partners.org

- Participation in women's mental health research

- Participation/involvement in psychiatric units designed to treat women with eating disorders

- Participation/involvement in psychiatric units designed to treat women with borderline personality disorder

\section{Special Degree(s)/Certificate(s) Offered}

None are offered.

\section{Goals of the Program}

Fellows will acquire knowledge and skills related to the expression and treatment of psychiatric disorders in women, including their relationship to sex, gender and reproductive cycle events.

\section{Other Program Features}

Brigham and Women's Hospital is a National Center of Excellence in Women's Health. The Gretchen S. and Edward A. Fish Center for Women's Health is an innovative, multi-specialty practice that co-locates specialty expertise in women's health and mental health with primary care for women. The Connors Center for Women's Health and Gender Biology focuses on women's health throughout the life span, promoting collaborative initiatives to improve patient care by translating research findings into clinical practice. The Connors Center conducts research on sex- and gender-based biology and the impact of sex and gender on disease, outcomes and the delivery of care.

Women's Hormones and Aging Research Program (WHARP) is a clinical and translational research group that aims to advance our understanding and treatment of symptoms resulting from estrogen fluctuations during the menopause transition, in the setting of breast cancer therapy, and other women's reproductive hormone transitions.

\section{Reason for Initiating Program}

This fellowship was designed to train clinicians to meet the growing need for expertise in women's mental health, utilizing a multifaceted conceptual framework to understand sex and gender influences on health and vulnerability to illness across the lifespan. 


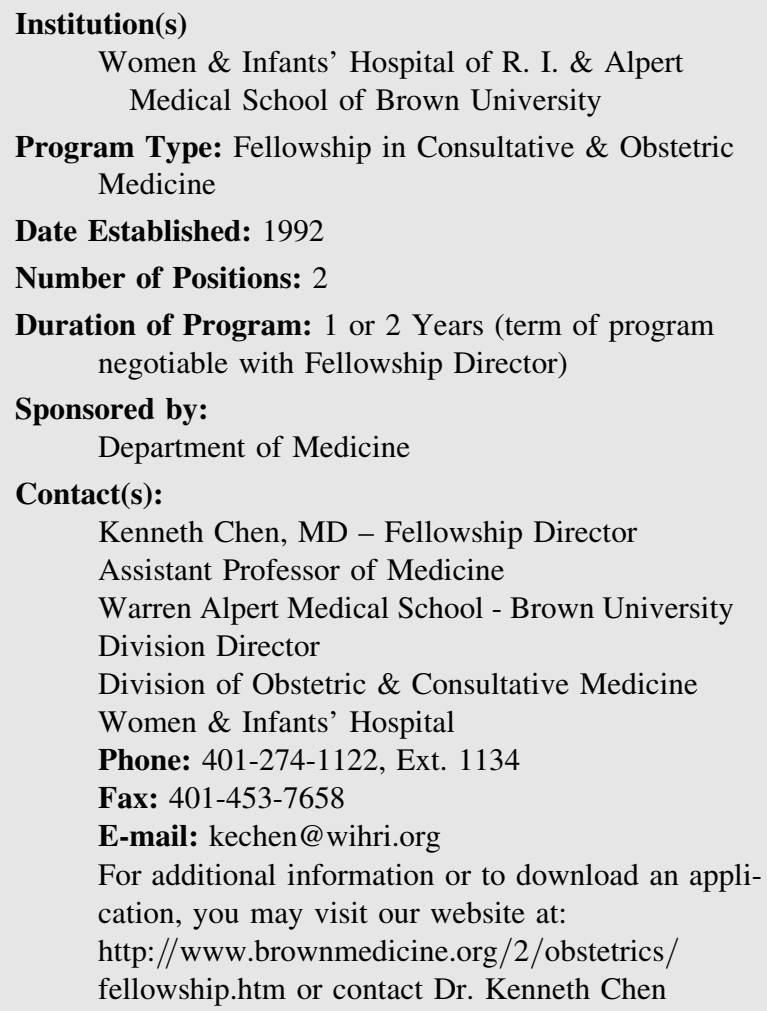

Date Established: 1992

Number of Positions: 2

Duration of Program: 1 or 2 Years (term of program negotiable with Fellowship Director)

Sponsored by: Department of Medicine

Contact(s):

Kenneth Chen, MD - Fellowship Director Assistant Professor of Medicine Warren Alpert Medical School - Brown University Division Director

Division of Obstetric \& Consultative Medicine Women \& Infants' Hospital

Phone: 401-274-1122, Ext. 1134

Fax: 401-453-7658

E-mail: kechen@wihri.org

For additional information or to download an application, you may visit our website at: http://www.brownmedicine.org/2/obstetrics/ fellowship.htm or contact Dr. Kenneth Chen

\section{Eligibility Requirements}

Evidence of promise as an educator and independent investigator in the area of consultative and obstetric medicine. Applicants should be board certified or board eligible internists. Medical graduates trained outside of the U.S. must be graduated from a school on the ECFMG list of approved international medical schools and complete ECFMG certification, pass a minimum of USMLE Steps $1 \& 2$, and obtain a J1 visa. Special arrangements may be made with Dr. Chen for Fellows active in another subspecialty program to serve an elective rotation for an optional term of 4 to 8 weeks.

\section{Required Activities}

Internists spend half of the two year program supervising an in-patient medical consultation service caring for the medically ill gravida. Fellows work directly with senior medical residents on the consult service, and are trained in both the doing and teaching of medical consultation in pregnancy. Two half days a week are spent in an ambulatory multidisciplinary consultative experience focusing on medical care of the pregnant woman, including participation in the Specialty Care in Pregnancy clinics focusing on specific areas, such as endocrinology, cardiology, hematology, rheumatology, gastroenterology, and obesity. Other time is spent working on clinical research projects and doing epidemiological and biostatistics course work at Brown University.

\section{Elective Activities}

A one-month elective rotation is open to second or third year internal medicine residents interested in learning more about consultative medicine with a special emphasis on medical problems in pregnancy. For more information, please contact Françoise Niang by calling 401-274-1122, Ext. 41925 or by email at fniang@ wihri.org.

\section{Special Degree(s)/Certificate(s) Offered}

A Certificate bearing the hospital seal and that of Brown University, signed by the Chief of Medicine and the Director of the Fellowship is issued to graduating Fellows in recognition of their service to Women \& Infants Hospital as a Fellow in Consultative and Obstetric Medicine during the stated training period.

\section{Goals of the Program}

Fellows work in both the inpatient and outpatient settings on the Medicine Consultation Service at Women and Infants' Hospital to acquire knowledge in the physiology of normal pregnancy and the pathophysiology of diseases occurring in pregnancy and postpartum; learn to diagnose and treat medical complications of pregnancy; learn to be an effective consultant to obstetricians and gynecologists and other internists and subspecialists; develop practical teaching skills through the supervision of senior medical residents and medical students. Fellows will also complete a research project in the area of medical problems in pregnancy. With the assistance of a faculty advisor, it is expected that the work will be presented at a national or international meeting and published in a peer review journal.

\section{Other Program Features}

Weekly fellows lecture series, fellows case presentations, fellows research meetings, journal club, Rhode Island Hospital grand rounds, OB/GYN grand rounds, medical consultation clinics, opportunities to enroll in Brown University courses in biostatistics and epidemiology, attendance at national meetings.

\section{Reason for Initiating Program}

Ground was broken in 1992 when the Department of Medicine, Women \& Infants' Hospital and the Warren Alpert School of Medicine of Brown University joined forces in first offering the fellowship in Obstetric \& Consultative Medicine. Prior to that time training in the evaluation and management of medical problems in the pregnant patient or those contemplating pregnancy was not available to the internist, nor were they exposed to the future health risks and pregnancy complications in these patients. Now there are 24 physicians who have completed the fellowship, the majority of whom have attained prominence in academic medicine around the world. 
Institution(s)

Warren Alpert Medical School of Brown University

Program Type: Women's Health and Sex and Gender in Emergency Medicine Fellowship

Date Established: 2012

Number of Positions: 1-2

Duration of Program: 2 years

Sponsored by:

Department of Emergency Medicine at

Brown University

Co-Sponsoring Institutions/Department: Women's

Cardiac Center at The Miriam Hospital, Department of Internal Medicine at Brown University, Lifespan's Women Medicine Collaborative, Hasbro Children's Hospital

Program Directors:

Alyson J. McGregor, MD, MA, FACEP

Director of Women's Health and Sex and Gender in Emergency Medicine Division

Co-Director of Women's Health in Emergency Medicine Fellowship

Assistant Professor of Emergency Medicine

Esther K. Choo, MD, MPH

Associate Director of Women's Health and Sex and Gender in Emergency Medicine Division

Co-Fellowship Director of Women's Health in Emergency Medicine Fellowship

Assistant Professor of Emergency Medicine

Women's Health and Sex and Gender

in Emergency Medicine Fellowship

593 Eddy Street, Providence, RI 02903

Telephone: 401-444-2739

Fax: 401-444-5166

Email: whec@lifespan.org

Contact:

Wendy Wesley

SGEM

55 Claverick Street, Providence, RI 02903

Telephone: 401-444-2739

Fax: 401-444-5166

E-mail sgem@lifespan.org

http://www.rhodeislandhospital.org/sgem/

\section{Eligibility Requirements}

Applicants must be graduating or have graduated from an accredited Emergency Medicine Residency. All applicants must:

- Provide a letter of interest, current CV and three letters of recommendation (including residency director)

- Apply to the Brown University MPH Program or similar advanced degree program

- Have an interest in women's health and sex and gender-specific emergency medicine, demonstrated through scholarly or advocacy experiences

- Previous research experience is preferred but not required

\section{Required Activities}

Fellows will provide clinical care of patients in a variety of settings, including Brown University affiliated emergency departments (Rhode Island Hospital Emergency Department and The Miriam Hospital Emergency Department) and Lifespan's Women Medicine Collaborative. Research mentorship will occur in the Women's Health and Sex and Gender in Emergency Medicine Division at The Department of Emergency Medicine at Warren Alpert Medical School of Brown University. Additional time will include attendance at conferences, lectures, quality assurance activities and quarterly meetings of the Division of Women's Health and Sex and Gender in Emergency Medicine.

\section{Elective/Optional Program Activities}

There are multiple clinical opportunities, including Lifespan's Women Medical Collaborative, The Women's Cardiac Center at The Miriam Hospital, and Hasbro Children's Hospital Adolescent clinic. This training, combined with mentored research projects and relevant clinical experiences, will provide outstanding preparation for a career focused on advancing the care of women in emergency medicine.

\section{Special Degrees/Certificates Offered (Include Additional Requirements, if any)}

The Fellow will have the opportunity to complete a Masters in Public Health at Brown University.

\section{Goals of the Program}

- Develop an understanding of the gaps in sex and gender-based research in emergency medicine

- Gain the skills necessary to practice comprehensive, gender-specific emergency medicine

- Receive didactic training and mentorship in performing research on women's health and sex and gender topics in emergency medicine

- Recognize ways to become active leaders in women's health and sex and gender locally and nationally

- Learn to promote access to high quality, culturally competent women's health and sex and gender care in emergency medicine 
- Develop competency in instruction of medical students, residents, and faculty in the area of women's health and sex and gender in emergency medicine

- Earn a Master's in Public Health (MPH) degree from Brown University

\section{Reason for Initiating Program}

This fellowship was designed to train clinicians to meet the growing need for expertise in women's health and sex and gender in emergency care and to utilize a multifaceted conceptual framework of understanding sex and gender influences on health as they relate to emergency medicine. 
Institution(s)

Case Western Reserve University/

University Hospitals Case Medical Center

Program Type: Fellowship in Women's Health

Date Established: 1999

Number of Positions: 2 per year

Duration of Program: 12 months

Sponsored by:

Department of Family Medicine, Case Western Reserve University/ University Hospitals Case Medical Center

Co-Sponsoring Institution(s)/Department(s): Louis Stokes Cleveland VA Medical Center

Contact(s):

Al Cadesky, MD, Fellowship Director 11100 Euclid Avenue

Cleveland, OH 44106-5036

Telephone: (216) $844-8375$

Fax: (216) 844-1030

E-mail: alan.cadesky@uhhospitals.org http://casemed.case.edu/fammed/education/ whfellowship.html

\section{Eligibility Requirement(s):}

Completion of ACGME or AOA accredited residency in Family Medicine; or American Board of Family Medicine or American Osteopathic Board of Family Practice certification is required.

\section{Required Activities}

- Precepting Medicine residents, performing Gyn procedures with a supervising $\mathrm{OB} / \mathrm{Gyn}$ attending and triaging abnormal Paps and mammograms for management at the weekly VA Gyn/Urgent followup/Preventive Health clinic;

- Coordinate weekly Women's Health lecture series for residents and medical students at the VA, including giving short talks on Women's Health topics and scheduling visiting lecturers;

- Scholarly activity at the VA on an ongoing project or another of your choosing;

- Patient care in UH Family Medicine Center including option for and encouragement of small continuity $\mathrm{OB}$ practice under preceptorship of Family Medicine attendings;

- Medical student teaching at UH both during patient care sessions and for required core clerkship in Medicine/Family Medicine in small group lectures and workshops;

- Colposcopy course faculty for UHCMC Family Medicine PGY2 course;

- Precepting Family Medicine residents at Adolescent clinic, Free Medical Clinic of Greater Cleveland and Care Alliance Health Center (homeless clinic), in rotation with other fellows.

\section{Elective Activities}

Gender-focused longitudinal or block experi ences at the VA and/or UH in female urology/urogynecology, Gyn, rheumatology, hematology-oncology, breast surgery, sports medicine, prevention, female psychiatry, sexual medicine, addiction/PTSD and others, tailored to your needs and interests.

\section{Special Degree(s)/Certificate(s) Offered}

Letter of completion.

\section{Goals of the Program}

The fellowship is intended to provide expanded training in various aspects of Women's Health while maintaining proficiency in the wider discipline of Family Medicine.

\section{Other Program Features}

Vacation and conference time as well as book money stipend are provided.

\section{Reason for Initiating Program}

To improve the health of women by training physicians in the comprehensive and complex needs of the female patient. 
Institution(s)

Cedars-Sinai Medical Center

Program Type: Fellowship in Women's Heart Disease and Health

Date Established: 2002

Number of Positions: 2 per year

Duration of Program: 1 year

Sponsored by:

1) Barbara Streisand Women's Heart Center, CedarSinai Heart Institute

2) The Constance A. Austin Fellow in Women's Heart Health

3) Edythe Broad Endowed Cardiology Research Fellowship

Contact(s):

C Noel Bairey Merz, MD, FACC, FAHA

Director, Barbra Streisand Women's

Heart Center

Cedars-Sinai Medical Center

127 S. San Vicente Blvd., AHSP-A3206

Los Angeles, CA 90048

Telephone: (310) 423-9680

Fax: (310) 423-3522

E-mail: merz@cshs.org

Website: www.csmc.edu/womensheart

\section{Eligibility Requirement(s)}

Medical Degree from accredited school.

Completion of a residency in internal medicine; completion of a clinical cardiology fellowship preferred... Unrestricted California license as Physician.

\section{Required Activities}

Under the direction of Dr. Bairey Merz, the Fellow will work with Dr. Bairey Merz in her pioneering research in the prevention and diagnosis of heart disease in women in this 1 year unaccredited fellowship. Specifically, the Fellow will participate and facilitate the clinical aspects of the ongoing research directed at improved understanding the sex and gender differences in heart disease, in order to translate these research findings into improved heart disease care for women.

\section{Didactic Components}

The fellows participate in the Cedars-Sinai Clinical Scholars Program which includes didactics in biostatistics, ethics, research study design, abstract/manuscript writing, grant writing and submission, research budgeting and contracting, and electives. Additional monthly conferences, journal club, Colloqui and quarterly Interdisciplinary Grand Rounds. Additional tutorials with Designated Mentor(s), as appropriate. Career Development Seminars, as well as additional didactic and ad hoc options are available through the UCLA and USC systems.

\section{Special Degree(s)/Certificate(s) Offered}

Fellows are eligible for the Cedars-Sinai Clinical Scholars Program (http://www.cedars-sinai.edu/Research-and-Education/ Departments/Biomedical-Sciencs/Clinical-Scholars-Program/)

Fellows are eligible for course work at UCLA leading to a Master of Public Health degree

\section{Goals of the Program}

To provide focused training in clinical and translational research with regard to heart disease in women, to train heart health practitioners in research, teaching, health administration and policy in women's health, and to respond to the needs of individual residents, fellows, faculty and voluntary staff regarding women's heart health in the medical institution and community.

The Women's Heart Center Teaching Faculty (Drs Bairey Merz, Shufelt, Mehta) will assess the activities and performance of the fellow, and will discuss the evaluations with the fellow. For the purpose of graduation, the fellow in this program is evaluated and must demonstrate competency in the following areas: 1) Patient care, 2) Medical knowledge, 3) Practice-based learning and improvement, 4) Interpersonal and communication skills, and 5) Professionalism

\section{Reason for Initiating Program}

The Women's Guild of Cedars-Sinai Medical Center raised money for the Women's Guild Endowed Chair in Women's Health in response to the awareness of improving Women's Health through education, research, and training. The current chair-holder, Dr. Bairey Merz, started this fellowship as part of a comprehensive Women's Health Program at Cedars-Sinai Medical Center. Current funding comes from philanthropic support. 


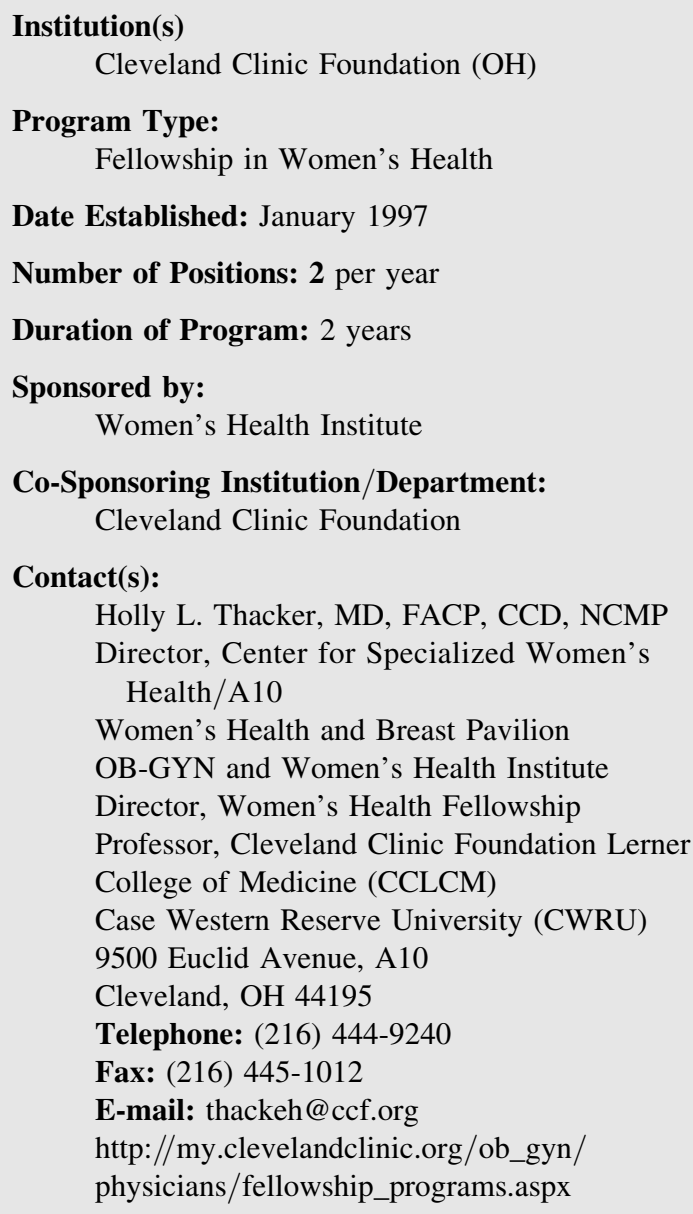

Date Established: January 1997

Number of Positions: 2 per year

Duration of Program: 2 years

Sponsored by:

Women's Health Institute

Co-Sponsoring Institution/Department: Cleveland Clinic Foundation

Contact(s): Holly L. Thacker, MD, FACP, CCD, NCMP

Director, Center for Specialized Women's Health/A10

Women's Health and Breast Pavilion OB-GYN and Women's Health Institute Director, Women's Health Fellowship Professor, Cleveland Clinic Foundation Lerner College of Medicine (CCLCM)

Case Western Reserve University (CWRU) 9500 Euclid Avenue, A10

Cleveland, $\mathrm{OH} 44195$

Telephone: (216) 444-9240

Fax: (216) 445-1012

E-mail: thackeh@ccf.org http://my.clevelandclinic.org/ob_gyn/ physicians/fellowship_programs.aspx

\section{Eligibility Requirement(s)}

Medical Degree from accredited school. Successful completion of residency in Internal Medicine or Family Medicine is required. Unrestricted Ohio license as a Physician is necessary upon commencement of program.

\section{Required Activities}

(1) This comprehensive fellowship includes clinical, collaborative, and interdisciplinary rotations. These core rotations include time spent in the Center for Specialized Women's Health which includes time in menopause clinic managing hormone therapy and participating in shared medical appointments addressing midlife concerns. Benign and office based gynecology spanning the reproductive years addressing basic gynecologic concerns, following pap smears and learning office based procedures as well as office based management of pelvic floor and voiding disorders and use of pelvic stimulation devices. Metabolic and osteoporosis bone clinic reading bone density scans, and breast rotations in the Women's Health and Breast Pavilion following the breast cancer survivor and workup of new masses and benign conditions. These core rotations provide the framework for gender based medicine practices that encompass chronic medical conditions as well.

(2) Completion of a longitudinal research project with a mentor on a gender based topic of interest. Building leadership and becoming a scholar are viewed as components of training.

(3) Trainees are expected to demonstrate leadership not only through research, but also through education, volunteer work, teaching, outreach projects, or other leadership positions, and also by attending national conferences, presenting scholarly work and building one's educational portfolio. Fellows are also expected to give and attend various grand rounds and journal clubs' of interest.

\section{Elective Activities}

Multiple offerings through the entire Cleveland Clinic Health system, as well as our geographic Center for Specialized Women's Health on the Main campus include but are not limited to adolescent medicine, sports medicine and the athletic triad, psychiatry and eating disorders, sexual medicine, pelvic floor physical therapy and chronic pelvic pain clinic, weight loss clinic, headache clinic, maternal-fetal medicine clinic, cardiology and prevention clinic, endocrinology, rheumatology and more as they pertain to the interests of the fellow.

\section{Special Degree(s)/Certificate(s) Offered}

A certificate of training as a Clinical Scholar specializing in Women's Health from the Cleveland Clinic is given. All fellows are expected to become NAMS credentialed menopause practitioners and have the option to become a certified clinical densitometrist. The Cleveland Clinic Learning Academy also offers a wide availability of courses aimed at covering material such as leadership, mentoring and teaching, which are available to take during your fellowship. Fellows also have the option to earn a Master of Public Health Degree or Masters in Education (every two years).

\section{Goals of the Program}

To create leaders and physician scholars, clinician-educators, and researchers in the areas of prevention and treatment of diseases unique or more prevalent in women relating to reproduction or midlife, and to gain a unique understanding of how gender based medicine plays a role in the management of chronic conditions. 
Other Program Features

Fellows will receive extensive education in women's health practice management (office based, clinical and procedural), learn to work in large multidisciplinary teams, learn medical business management, and will be successfully trained to direct or run a Women's Health specialized center if they so choose, as fellows are taught to be leaders and scholars in the field of Women's Health. Fellows also have extensive opportunities to teach undergraduate residents and are involved in the education of IM, FP and OB/GYN residents and medical students. A course in research fundamentals is offered monthly throughout the fellowship. Fellows are encouraged to self-select electives geared towards their ultimate career goals or research work.

\section{Reason for Initiating Program}

The fellowship was developed out of the interest of the faculty in sharing Cleveland Clinic's available resources for the exploration and study of menopause and gender related aspects of illness. 


\section{Institution(s) \\ Columbia University Medical Center}

Program Type: Women's Health Scholar Program

Date Established: 2003

Number of Positions: 1 per year

Duration of Program: 1 year

Sponsored by:

Department of Obstetrics and Gynecology

Contact(s):

Michelle Warren, MD

Professor of Medicine and

Obstetrics and Gynecology

PH 16-128

Columbia Presbyterian Medical Center

622 West $168^{\text {th }}$ Street

New York, NY 10032

Telephone: 212-305-8723

E-mail: mpw1@columbia.edu

\section{Eligibility Requirements}

A medical degree is required and the candidates must be board eligible in their specialty. These can include Obstetrics and Gynecology, Internal Medicine, Endocrinology, Family Medicine, or Primary Care.

\section{Required Activities}

The Women's Health Scholar is a position offered for one year for training in the research and practice of menopause and hormonal disorders and women's health. The training will include participation in the management of clinical trials, and original grant research as well as attendance at the clinical research seminar series. Training will include menopause management including osteoporosis, perimenopause, lowering risk factors for chronic disease, mood disorders in the hormonally vulnerable women, management of the high risk breast cancer patient and the diagnosis and management of menstrual disorders in pre and post menopausal women including polycystic ovarian syndrome and hypothalamic amenorrhea. Training will also include common endocrine disorders both in young women and post menopausal women.

\section{Elective Activities}

Electives are offered to trainees in osteoporosis and various research areas.

\section{Special Degree(s)/Certificate(s) Offered}

No degrees are offered.

\section{Goals of the Program}

The goal of the program is to provide a broad base of training in women's health including menopause management, office gynecology, common endocrine and medical and gynecologic problems of women so that coordinated care may be provided by one physician.

\section{Other Program Features}

The Scholar will be expected to do independent research and will receive training in grants submissions, both pharmaceutical and NIH funded. Scholars will be expected to publish and lecture on the subject of their chosen research. Part-time positions will be considered.

\section{Reason for Initiating Program}

The availablity of the Center for Menopause Hormonal Disorders and Women's Health as a clinical resource and the demand for better training in women's health. 


\section{Institution(s) \\ Brody School of Medicine at East Carolina University}

Program Type: Fellowship in Women's Health

Date Established: 2001

Number of Positions: 1 per year

Duration of Program: 1-2 years

Sponsored by:

East Carolina University

Co-Sponsoring Institution(s)/Department(s):

Department of Family Medicine and Center for the Advancement of Women's Health

Contact(s):

Dorothy Butler, MD, PhD

Telephone: (252) 744-5517

Fax: (252) 744-4614

E-mail: butlerd@ecu.edu

Website: www.ecu.edu/cs-dhs/fammed/

fellowships/women-fellow-overview.cfm

\section{Eligibility Requirement(s)}

North Carolina Board Certified/Board Eligible Family Physician.

\section{Required Activities}

Breast Clinic (3 months); Obstetrical Ultrasound (Longitudinal); Faculty Development Course; Skills Clinic; Maternity Care Clinic (OB Fellow only-Longitudinal); Prenatal Care Clinic (OB Fellow only); Labor and Delivery call is one evening per week and one weekend per month with Family Medicine Attending Physician Supervision; one Grand Rounds presentation during one-year fellowship; Participation in teaching activities in the resident curriculum; Creative activity encouraged.

\section{Elective Activities}

Maternal Fetal Medicine; Chronic Pelvic Pain Clinic; Behavioral Medicine; Lactation Consultation; Nutrition; Other Specialty of Choice (Will be arranged by fellowhip director upon request of fellow).

\section{Special Degree(s)/Certificate(s) Offered}

Certificate offered.

\section{Goals of the Program}

To support training for primary care physicians in comprehensive and coordinated women's health primary care and formalizing women's health training in the attitudes, knowledge, and skills required to respond to the special health care needs of women.

\section{Other Program Features}

Concentration could include clinical strategies in curriculum development or clinical teaching. Clinical appointments are held in the Department of Family Medicine.

\section{Reason for Initiating Program}

To support the mission of the Brody School of Medicine at East Carolina University to improve the health care of eastern North Carolina through the advancement of medical education and research. The fellowship program seeks to improve the health professional training in primary care of women by establishing academic and community leaders in women's health care. 


\section{Institution(s)}

Edward Hines Jr. VA Hospital and Loyola University Stritch School of Medicine

Program Type: Psychiatry (Women's Mental Health)

Date Established: 2014

Number of Positions: 1 (PGY-4 only)

Sponsored by:

Mental Health Service Line (Hines VA);

Department of Psychiatry (Loyola University)

\section{Contact(s):}

Medical Director of Women's Mental Health

Professor of Psychiatry

Edward Hines Jr. VA Hospital

5000 S. 5th Avenue

Bldg. 228, Rm. 1016

Hines, IL 60141

Telephone: 708-202-5137

Fax: 708-202-2085

E-mail: laura.miller8@va.gov

Michelle R. Armstrong, MA

Residency/Fellowship Coordinator - Neurology, Psychiatry and Behavioral Neurosciences

Loyola University Medical Center

Mcguire Building

2160 S. First Avenue

Maywood, IL 60153

Telephone: 708-216-2687

Fax: 708-216-5885

E-mail: michelle.armstrong@luhs.org
Laura J. Miller, MD

\section{Eligibility Requirement(s)}

Completion in good standing of psychiatry residency through PGY-3 year.

\section{Required Activities}

Outpatient psychiatric care in an integrated primary care clinic; outpatient psychiatric care in an academic women's mental health clinic; scholarly/career development project; women's mental health didactics; teaching women's mental health to Internal Medicine residents.

\section{Elective Activities}

Gynecology clinic; sexual dysfunction clinic

\section{Other Program Features}

The Hines/Loyola Women's Mental Health Fellowship offers the unique experience of working in a collaborative care Women's Health Clinic that includes women's health primary care physicians, gynecologists, nurses, women's mental health psychiatrists, social workers, a psychologist, a clinical pharmacist and a nutritionist. It also includes clinical experiences in an academic specialty outpatient women's mental health clinic which focuses on perinatal mental health care. This fellowship includes a particular focus on the mental health needs of women veterans, a unique and growing population.

\section{Reasons for Initiating Program}

Numerous studies have amply demonstrated that integrating mental health care into primary care and women's health settings is clinically effective and cost effective. Traditional psychiatry residency programs rarely train residents in the unique skills required to be effective in integrated care settings. In addition, many psychiatry residencies do not yet adequately cover the influence of sex, gender and reproductive cycle stages on mental health, psychopathology and psychiatric treatment. This residency specialty track/fellowship is designed to fill these gaps. It is especially important to train psychiatrists to be skilled in meeting the needs of women veterans, given projections that women are comprising an increasingly large percentage of total veterans and have substantial need for mental health care. 
Institution(s)

MacNeal Hospital

Program Type: Fellowship in Women's Health

Date Established: July 1995

Number of Positions: 1 per year

Duration of Program: 1 year

Sponsored by:

MacNeal Hospital Family Medicine

Residency Program

$\operatorname{Contact}(\mathbf{s})$ :

Amy E. Harrison, MD

Director of Women's Health Fellowship

MacNeal Hospital

3231 South Euclid

$5^{\text {th }}$ Floor

Berwyn, IL 60402

Telephone: (708) 783-3094

E-mail: aeharris@macneal.com

http://www.macneal.com/residency-programs/

family-medicine-residency/fellowships/

womens-health-fellowship.aspx

\section{Eligibility Requirement(s)}

Completion of a Family Practice residency program (preferred) or an Internal Medicine Residency is required.

\section{Required Activities}

Longitudinal care of patients in the Family Medicine Center with clinical rotations in a variety of areas of women's health. The fellow is required to complete a research or scholarly project in the fellow's area of interest (e.g. eating disorders, women's heart health, breastfeeding, and sports medicine).

\section{Elective Activities}

Fellows assist the faculty in teaching residents and medical student in full-spectrum family medicine, including gynecological procedures and obstetrics. Fellows can also participate in faculty development seminars (e.g. adult learning theory, curriculum design, epidemiology, etc.) along with our faculty development fellow. We offer a supportive and flexible environment that encourages the fellow's individual interests.

\section{Special Degree(s)/Certificate(s) Offered}

None are offered.

\section{Goals of the Program}

To provide advanced training in the broad spectrum of women's health.

\section{Other Program Features}

Information was not provided.

\section{Reason for Initiating Program}

This fellowship was started to provide advanced training in women's health. It is designed for clinicians interested in obtaining advanced training in the broad spectrum of women's health. 


\section{Institution(s) \\ Mayo Clinic College of Medicine (MN)}

Program Type: Fellowship in Women's Health

Date Established: 1997

Number of Positions: Up to 3 positions per year potentially available.

Duration of Program: 1-2 years

Sponsored by:

Department of Medicine

Contact(s):

Nicole P. Sandhu, MD, FACP, PhD

Mayo Clinic School of Graduate Medical

200 First Street SW Rochester,

MN 55905

E-mail: sandhu.nicole@mayo.edu

Telephone: 507-538-7946

Fax: 507-266-3988

Cori Chvosta, Educational Coordinator

E-mail: chvosta.cori@mayo.edu

Website: www.mayo.edu/msgme/

womenshealth-rch.html
Education

\section{Eligibility Requirement(s)}

Completion of an accredited residency in Internal Medicine, Family Medicine or Obstetrics and Gynecology.

\section{Required Activities}

The Women's Health Training Track in the General Internal Medicine Fellowship provides advanced clinical training in areas relevant to the health of women through the adult lifespan. Fellows will complete a 1 year multidisciplinary training program with the option to complete a second year, depending on the fellow's goals and successful completion of the first year. The second year may focus on research or another approved focus of training activity. Fellows may also choose a 2 year program including didactic course work toward a Master in Public Health (MPH) through a partnership with the University of Minnesota-Rochester campus followed by 1 year of multidisciplinary clinical training and scholarly activity. Required clinical rotations for all fellows include: Women's Health Clinic (focused on sexual and menopausal medicine), Medical and Surgical Gynecology (including Gynecology Oncology), Maternal-Fetal Medicine, Obstetrics, Urogynecology, Bone Clinic, Nutrition Clinic, Medical and Reproductive Endocrinology, Breast Health (including Breast Diagnostic and Cancer Clinics, Breast Imaging and Breast Surgery) and Women's Cardiovascular Clinic. Numerous elective clinical rotations are available and will be decided upon by the fellow with the input of the Program Director to design a clinical training program suited to the specific interests and career goals of each trainee. Fellows are expected to participate in monthly journal clubs and other educational activities.

\section{Elective Activities}

Clinical rotations are available in areas including but not limited to Complimentary and Integrative Medicine, Psychiatry, Dermatology, Headache Clinic, Nicotine Dependence, Pain Clinic, Rheumatology and Spine Clinic.

\section{Special Degree(s)/Certificate(s) Offered}

Certificate offered. Degree offered depending on training track and options chosen.

\section{Goals of the Program}

The Women's Health Fellowship at Mayo Clinic combines interdisciplinary training in the prevention, diagnosis and treatment of health conditions specific to women, more common or more serious in women, having distinct causes, manifestations, outcomes or treatments in women and/or having high morbidity or mortality in women.

\section{Other Program Features}

Fellows participate in Faculty Development including training in medical education. A wide variety of teaching and additional educational opportunities are available. Fellows may choose to complete the Clinical Research Training Program or a Master of Science in Clinical Research as part of a two year training program. Mayo Clinic has been awarded NIH funding for the Building Interdisciplinary Research Careers in Women's Health program(BIRCWH), a career development grant which supports young faculty focused on careers in women's health research, offering educational and collaborative opportunities to our fellows.

\section{Reason for Initiating Program}

To develop leaders in the evolving field of Women's Health, to advance discovery in areas of medicine relevant to the health of women and to improve health care outcomes for women. 
Institution(s)

Medical College of Wisconsin/Milwaukee Veterans Affairs Medical Center

Program Type: Fellowship in Women's Health

Date Established: 2012

Number of Positions: 2 per year

Duration of Program: 2 years

Sponsored by:

Medical College of Wisconsin Department of Medicine, Division of General Medicine and Milwaukee Zablocki VA Medical Center

Co-sponsoring Institutions or Departments:

Departments of Obstetrics \& Gynecology, Urology, and Psychiatry

Program Director:

Kathryn Havens, MD

Associate Professor of Medicine

Medical College of Wisconsin

Director of Women's Health

Zablocki VA

5000 W. National Avenue

Milwaukee, Wisconsin 53295

Telephone: 414-384-2000 red clinic

E-mail: Kathryn.Havens@Va.Gov

Website: http://www.mcw.edu/

generalinternalmed/fellowship/

womenshealth.htm

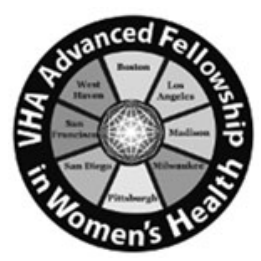

\section{Eligibility Requirement(s)}

We have two tracks: MD and PhD. Requirements for MD include completion of a residency program and board-eligible in medicine, family medicine, psychiatry, obstetrics \& gynecology or urology. Requirements for $\mathrm{PhD}$ include completion of doctoral degree in allied health fields such as psychology and nursing.

\section{Required Activities}

Fellows must complete an individualized learning plan approved by the program director and advisory board. This plan will define the required activities commensurate with the fellow's career goals. Typical required activities for the MD track include $25 \%$ clinical effort, where at least one half-day weekly is spent at the VA women's health clinic, plus 75\% academic development in research, education, or quality. Typical required activities for the Allied Health track are similar to PhD Nursing and Psychology post-docs, where the fellow will conduct research or quality projects and participate in the VA Women's Health clinic operational innovations.

\section{Elective Activities}

Fellows may elect a full complement of women's health clinical activities including multidisciplinary comprehensive women's health (with medicine, gynecology, and mental health input), consultative women's health (with a focus on midlife, wellbeing, incontinence and sexual health), and subspecialty women's health (such as osteoporosis, breast, contraception, and women's mental health clinics). Depending on the fellow's career goals, fellows may pursue mentored research, educational administration, teaching, quality projects, and clinical innovations.

\section{Special Degrees/Certificates Offered:}

Master's program in Public Health, Clinical and Translational Science, or Bioethics. Special seminars in teaching and educational administration and health statistics.

\section{Other Program Features:}

Fellows can collaborate within the program (MD and PhD collaboration) and can collaborate with the Medical College of Wisconsin's Primary Care Fellows (sponsored by a HRSA Fellowship). Fellowship faculty include the full range of investigators, educators and clinicians at our large academic medical center.

\section{Goals of the Program:}

To advance the health care of women, particularly veterans, and develop academic women's health providers and researchers.

\section{Reason for Initiating Program}

To create a critical mass of energetic minds from multiple fields, all focused on women's health. 
Institution(s)

Portland Veterans Affairs Medical Center/

Oregon Health \& Science University

Program Type: Fellowship in Women's Health

Date Established: June 1994

Number of Positions: 1-2 per year

Duration of Program: 2 years

Sponsored by:

Department of Medical Services

Co-Sponsoring Institution(s)/Department(s): Oregon Health and Science University

Contact(s):

Linda Humphrey, MD, MPH

Director of Women's Health Fellowship

Portland Veterans Affairs Medical Center

3781 SW US Veterans Hospital Road

Portland, OR 97207

Telephone: (503) 220-8262 x-57176

Fax: (503) 721-7807

E-mail: humphrey@ohsu.edu

Website: www.ohsu.edu/gim/

fellowships/women.cfm

\section{Eligibility Requirement(s)}

Completion of a residency in Internal Medicine, Surgery, Psychiatry, Obstetrics and Gynecology, or Family Medicine is required.

\section{Required Activities}

Seventy-five percent of the program is devoted to research and teaching and $25 \%$ is devoted to clinical activities.

\section{Elective Activities}

The following clinics are available: Breast, Psychiatry, Domestic Violence, Adolescent Medicine, Gynecology, Urogynecology, Osteoporosis, Endocrinology, and Behavioral Medicine.

\section{Special Degree(s)/Certificate(s) Offered}

An optional third year is available based upon individual fellowship goals. Master of Public Health degrees and Human Investigation Program (HIP) certificates are also available.

\section{Goals of the Program}

To train individuals for an academic career which includes research and teaching in women's health.

\section{Other Program Features}

Our program is closely allied with fellowships in Hospital Medicine, General Internal Medicine, Informatics, and Geriatrics. We have a strong relationship with OHSU's AHRQ-supported Evidence-based Practice Center.

\section{Reason for Initiating Program}

Our institution, in conjunction with the Oregon Health Sciences University, has the components to provide excellent training in women's health, research methodology, and education. 
Institution(s)

San Francisco Veterans Affairs Medical Center

Program Type: Fellowship in Women's Heart Disease and Health

Date Established: 1993

Number of Positions: 2 per year

Duration of Program: 2 years

Sponsored by:

Medical Service of San Francisco Veterans Affairs Medical Center

Co-sponsoring Institutions or Departments: University of California, San Francisco

Program Director

Karla Kerlikowske, MD

Medical Director

Contact Person for Applicants:

Carla Li

4150 Clement Street

San Francisco, CA 94121

Telephone: (415) 750-2093

Fax: (415) 353-9790

E-mail: Carla.Li@va.gov

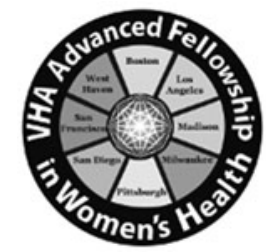

\section{Eligibility Requirement(s)}

Applicants must have a Medical Degree (MD) and have completed an approved residency or Doctorate of Philosophy $(\mathrm{PhD})$ in psychology, nursing or pharmacology.

\section{Required Activities}

At the start of the 2-year program, fellows and senior mentors will develop a training plan that is tailored to the background and interests of each fellow and the resources available at the SFVAMC and UCSF. We expect fellows to develop content and methodologic expertise, strong communications skills, and experience and skill in building and leading teams. In the first year, fellows will complete the UCSF Advanced Training in Clinical Research (where they may elect to obtain a Masters Degree in Clinical Research) and may also take courses from the UCSF Programs in Biological Sciences and Biomedical Sciences (www.epibiostat.ucsf.edu). Advanced Training in Clinical Research includes training in core disciplines including epidemiologic methods, biostatistics, clinical trials, molecular methods, medical informatics, scientific writing, grant preparation, and research ethics. The second year will focus on completion of research and writing projects under the supervision of senior faculty. Mentors will provide access to existing databases and repositories of biological specimens, advice in selection of research projects, assistance in study design and performance, guidance in ethical conduct of research and career counseling. A Women's Health Research Seminar will provide an opportunity for fellows to present work in progress, address methodologic issues and improve writing and presentation skills.

\section{Goals of the Program:}

The San Francisco Veterans Affairs Medical Center is dedicated to developing a cadre of well-trained researchers in women's health to advance healthcare for women veterans.

\section{Reason for Initiating Program}

To train clinical researchers to advance knowledge in women's health through conducting high quality, clinically relevant research. 


\section{Institution(s)}

VA Greater Los Angeles Healthcare System (CA)

Program Type: Fellowship in Women's Health

Date Established: 1992

Number of Positions: 2 per year

Duration of Program: 2 years

Sponsored by:

VA Special Fellowship Program

Co-Sponsoring Institution(s)/Department(s):

UCLA Medical Center/RAND

Contact(s):

Program Directors:

Lisa Altman, MD

ACOS for Primary Ambulatory CARE \& PACT

E-mail: lisa.altman@va.gov

Donna Washington, MD

VA GLA Women's Health

E-mail: donna.washington@va.gov

Contact for Applicants:

Britney Chow, MPH

Program Coordinator

16111 Plummer Street

Bldg 25, Rm B108

North Hills, CA 91343

E-mail: britney.chow@va.gov

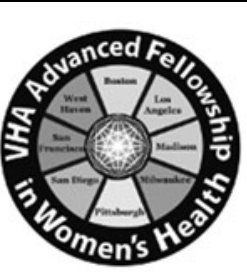

\section{Eligibility Requirement(s)}

Completion of an accredited residency training program or of a doctoral degree in an associated health field; US citizenship or a current visa and an ECFMG certificate; physicians must be board certified or eligible in internal medicine, $\mathrm{Ob} / \mathrm{Gyn}$, family medicine, psychiatry, or surgery.

\section{Required Activities}

$75 \%$ time research, including master's level classes in epidemiology and statistics, and teaching interns/residents; and $25 \%$ clinical time.

\section{Elective Activities}

No information provided.

\section{Special Degree(s)/Certificate(s) Offered}

Master's in Public Health.

\section{Goals of the Program}

To train creative, independent, ethical and productive leaders in health services research and related fields, and to produce outstanding practitioners (proficient as researchers, clinicians, and educators) for academic VA positions in the area of women's health, in order to advance and improve VA women's healthcare as well as the VA women's healthcare delivery system.

\section{Other Program Features}

This fellowship, funded by the Department of Veterans Affairs, is open to primary care physicians, obstetricians and gynecologists who are interested in research in women's health. Fellows in this program also develop competencies in clinical care for women, including performance and minor gynecologic procedures, through the VA Women's Health Center program. Fellows complete a core curriculum including formal course work, usually leading to a degree, at the UCLA School of Public Health; informal course work in fellowship seminars; and an independent research project.

\section{Reason for Initiating Program}

This fellowship program was awarded as the result of a competitive application process through the Department of Veterans Affairs. It supports our mission to provide comprehensive, coordinated healthcare and education, based on women's life cycles, to women veterans and allow Fellows multidisciplinary clinical practice and research opportunities. 


\section{Institution(s) \\ UCSF Women's Health Clinical Research Center}

Program Type: Fellowship in Women's Health

Date Established: 2002

Number of Positions: 1 per year

Duration of Program: 2 years

Sponsored by:

Departments of Obstetrics and Gynecology

and Epidemiology and Biostatistics

Contact(s):

Leslee Subak, MD

Director

UCSF Women's Health Clinical Research

Fellowship

Mailstop 1793

550 16th Street, 6th floor

San Francisco, CA 94143

Telephone: (415) 353-9751

Fax: (415) 476-5367

E-mail: Leslee.Subak@ucsf.edu

Fellowship website: www.whcrc.ucsf.edu

\section{Eligibility Requirement(s)}

Applicants must have a Medical Degree (MD or DO) and have completed an approved residency.

\section{Required Activities}

At the start of the 2-year program, fellows and senior mentors will develop a training plan that is tailored to the background and interests of each fellow and the resources available at UCSF. We expect fellows to develop content and methodologic expertise, strong communications skills, and experience and skill in building and leading teams. In the first year, fellows will complete the UCSF Advanced Training in Clinical Research (where they may elect to obtain a Masters Degree in Clinical Research) and may also take courses from the UCSF Programs in Biological Sciences and Biomedical Sciences (www.epibiostat.ucsf.edu). Advanced Training in Clinical Research includes training in core disciplines including epidemiologic methods, biostatistics, clinical trials, molecular methods, medical informatics, scientific writing, grant preparation, and research ethics. The second year will focus on completion of research and writing projects under the supervision of senior faculty. Mentors will provide access to existing databases and repositories of biological specimens, advice in selection of research projects, assistance in study design and performance, guidance in ethical conduct of research and career counseling. A Women's Health Research Seminar will provide an opportunity for fellows to present work in progress, address methodologic issues, and improve writing and presentation skills. For complete details, please visit http://www.epibiostat.ucsf.edu.

\section{Elective Activities}

For complete details, please visit http://www.epibiostat.ucsf.edu.

\section{Special Degree(s)/Certificates(s) Offered}

Master's Degree in Clinical Research. For complete details, please visit http://www.epibiostat.ucsf.edu.

\section{Goals of the Program}

To develop a cadre of well-trained clinical researchers in women's health.

\section{Other Program Features}

At the start of the 2 year program, fellows and senior mentors will develop a training plan tailored to the background and interests of each fellow and the resources available at UCSF. Fellows are expected to develop content and methodologic expertise, strong communications skills, and experience and skill in building and leading teams.

\section{Reason for Initiating Program}

To train clinical researchers to advance knowledge in women's health through conducting high quality, clinically relevant research. This fellowship program builds on the research success of UCSF, the institution's commitment to women's health, and the availability of an extensive array of ongoing research projects to develop a cadre of well-trained clinical researchers in women's health. 


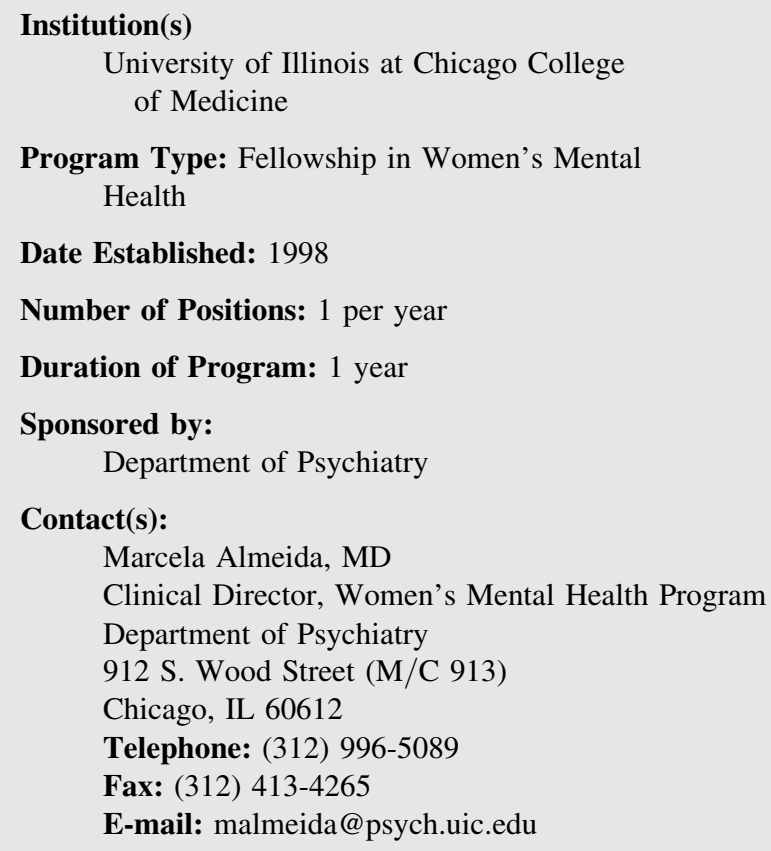

Date Established: 1998

Number of Positions: 1 per year

Duration of Program: 1 year

Sponsored by:

Department of Psychiatry

Contact(s):

Marcela Almeida, MD

Clinical Director, Women's Mental Health Program Department of Psychiatry

912 S. Wood Street (M/C 913)

Chicago, IL 60612

Telephone: (312) 996-5089

Fax: (312) 413-4265

E-mail: malmeida@psych.uic.edu

\section{Eligibility Requirement(s)}

Completion of 3 years postgraduate training in psychiatry, and must be in $4^{\text {th }}$ year of training.

\section{Required Activities}

Rotations through the 3 different Women's Clinic one of which is in the department of Obstetrics and Gynecology; participation and coordination of Women's Consultation Service; participation in the Women's Mental Health Seminar, and the Women's Mental Health Tutorial; supervision of fourth-year medical students during Women's Mental Health electives.

\section{Elective Activities}

Participation in the Illinois Perinatal Mental Health Project; rotations through the Women's Inpatient Treatment Service and/or the Eating Disorders Clinic; teaching in the Women's Mental Health Seminar; co-leading peripartum group.

\section{Special Degree(s)/Certificate(s) Offered}

None are offered.

\section{Goals of the Program}

Fellows will acquire knowledge and skills related to the expression and treatment of psychiatric disorders in women, including their relationship to reproductive cycle events.

\section{Other Program Features}

Research experience related to women's mental health and a didactic curriculum in women's mental health are offered. Fellows will have opportunities to publish and review articles and/or book chapters. This program has received the American College of Psychiatrists' Award for Creativity in Psychiatric Education and the American Psychiatric Association's Gold Award for Innovative Services.

\section{Reason for Initiating Program}

This fellowship was designed to train clinicians to meet the growing need for expertise in women's mental health by applying research findings to clinical practice, and teaching state-of-the-art interventions. 
Institution(s)

Rutgers University/Robert Wood Johnson Medical School

Program Type: Reproductive Health in Family Medicine Fellowship

Date Established: July 1992

Number of Positions: 1 per year

Duration of Program: 1 year

Sponsored by:

Department of Family Medicine and Community Health

Co-Sponsoring Institution(s)/Department(s): Department of Obstetrics, Gynecology, and Reproductive Science

Contact(s):

Jeffrey P. Levine, MD, MPH (Co-Director)

Justine $\mathrm{Wu}, \mathrm{MD}, \mathrm{MPH}$ (Co-Director)

Department of Family Medicine and Community Health

Rutgers University-Robert Wood Johnson Medical School

One Robert Wood Johnson Place, CN19

New Brunswick, NJ 08903-0019

Telephone: (732) 235-7669 (Fellowship

Coordinator: Robin Covington)

Fax: (732) 235-6309

E-mail: covingra@umdnj.edu

Website: http://rwjms.umdnj.edu/

departments_institutes/family_medicine/

fellowships/women/index.html

\section{Eligibility Requirement(s)}

A New Jersey medical license and board eligibility in Family Medicine.

ACLS certified (for moderate sedation licensing)

\section{Required Activities}

Training in first trimester abortion care (options counseling, medication abortion and aspiration abortion) to trainer-level competence in a high-volume family planning clinic AND a family medicine outpatient office; training in family planning, including provision of long-acting reversible contraceptives (LARC) to trainer-level competence; original scholarly research project design and implementation and dissemination of results via peer-reviewed publications and/or scholarly presentations; resident and medical student teaching during Women's Health Rotation and Student Electives; clinical sessions and establishment of continuity patient panel at Rutgers Student Health; local and national $\mathrm{CME} /$ research presentations; clinical rotations in selected areas of women's health; community service/outreach tailored to the individual's interests; practice-based quality improvement initiatives tailored to the individual's interest.

\section{Elective Activities}

Opportunities for clinical rotations in Breast Disorders, Urogynecology, Reproductive Endocrinology, and STI Clinics can be arranged based upon the individual's interests. Fellows are encouraged to take a leadership role in addressing women's health issues most relevant to them, utilizing our educational, clinical, community, and legislative resources. Fellows are also invited to participate in women's health related clinical trials, educational programs, and professional organizations.

\section{Special Degree(s)/Certificate(s) Offered}

None were specified.

\section{Goals of the Program}

To develop leaders in women's reproductive health care, education, research and advocacy.

\section{Other Program Features}

This program provides outstanding hands-on abortion and LARC training opportunities, excellent medical student and resident teaching experience, and the ability to provide reproductive health care in a variety of settings including a dedicated family planning clinic, an academic family medicine office and a university student health service. Fellows will graduate with an appreciation for and expertise in the provision of family planning and abortion services in multiple health settings, particularly in primary care. We encourage the fellows to tailor their clinical rotations and scholarly projects to their interests and future career goals. Fellows receive high-quality, consistent mentorship from experienced faculty members with expertise in medical education, family planning and abortion care.

\section{Reason for Initiating Program}

To develop and coordinate the essential resources and opportunities for Family Physicians to become abortion and LARC providers, trainers, and women's reproductive health care advocates. 


\section{Institution(s)}

University of Michigan School of Medicine

Program Type: Fellowship in Women's Health

Date Established: 2004

Number of Positions: 1-2 per year

Duration of Program: 1 year

Sponsored by:

Women's Health Program

Contact(s):

Carrie Bell, MD

Department of Obstetrics and Gynecology

University of Michigan

1500 E. Medical Center Drive, L4000

Ann Arbor, MI 48109-5276

Telephone: 734-615-3773

Fax: 734-936-7507

E-mail: pengel@med.umich.edu

\section{Eligibility Requirement(s)}

Completion of residency in Family Medicine, Internal Medicine, Obstetrics/Gynecology, Pediatrics, or Psychiatry is required, further subspecialty training favorably considered.

\section{Required Activities}

Selected rotations in the Women's Health Clinic, Obstetrics and Gynecology Primary Care Clinic, Endocrinology and Metabolism Eating Disorders, Cardiology GI, Mental Health, Sexual Dysfunction, Geriatrics. Attend University of Michigan BIRCWH Seminar Series.

\section{Elective Activities}

Family Planning, Adolescent Gynecology, International Rotation, Institute for Research on Women and Gender

\section{Special Degree(s)/Certificate(s) Offered}

Certificate of Completion

\section{Goals of the Program}

Unsurpassed preparation for clinically focused Women's Health specialty or academic Women's Health careers.

\section{Other Program Features}

The fellowship offers a one year clinical training fellowship with selected rotations at the various entities within the Women's Health Program at the University of Michigan (examples include the Women's Cardiac Program, the Women's GI Program, the Women's Mental Health Program, the Women's Pulmonary Clinic, the multidisciplinary Adolescent clinic, Hi Risk Ob Clinic including the substance abuse directed Partnering for the Future clinic, the Michigan Bowel/Incontinence Program, Medical Complications Contraception clinic, Pregnancy Loss Clinic, Center for Reproductive Medicine, and numerous other components of the UM Women's Health Program). Each fellow has an individualized curriculum to reflect past training that is designed to meet her/his specific goals and objectives. Multi-disciplinary clinical and research mentorship is available for each fellow. A series of scholarly outputs and research experiences are expected of each fellow. Participation in career development programs (e.g. BIRCWH) at the University of Michigan are expected and include mandatory participation in core department fellowship curricular offerings in medical education, career skills, leadership training and research techniques.

\section{Reason for Initiating Program}

To train clinical and academic leaders in a rich collaborative environment utilizing the resources of the University of Michigan Women's Health Program. 
Institution(s)

Pittsburgh Health Care System

University of Pittsburgh Medical Center/

University of Pittsburgh School of Medicine

Program Type: Fellowship in Women's Health

Date Established: June 1995

Number of Positions: 1-2 per year

Duration of Program: 2 years

Sponsored by:

Department of Medicine

Co-Sponsoring Institution(s)/Department(s): Institute for Clinical Research Education

\section{Contact(s):}

Melissa McNeil, MD, MPH

Professor of Medicine and Obstetrics,

Gynecology and Reproductive Sciences

Division of General Internal Medicine

UPMC Montefiore, Suite W933

200 Lothrop St

Pittsburgh, PA 15213

Telephone: 412-692-4821

Fax: 412-692-4825

E-mail: mcneilma@upmc.edu

Website: http://www.residency.dom.pitt.edu/

Program_Overview/tracks/womens_health.html

life, women and obesity, and cardiovascular disease in women. Educators have opportunities to work both at the medical student and resident level. The training program is always tailored to the individual's needs.

\section{Special Degree(s)/Certificate(s) Offered}

Either a Master's in Medical Education or a Master's in Clinical Science.

\section{Goals of the Program}

To train generalist physicians with an interest in academic women's health.

\section{Other Program Features}

This program partners with the following University of Pittsburgh programs: Clinical and Translational Science Institute, General Medicine Fellowship Program, Magee Women's Hospital, RAND Corporation, University of Pittsburgh School of Public Health, and the University of Pittsburgh School of Medicine.

\section{Reason for Initiating Program}

To develop training programs designed to expand the faculty expertise in women's health in both the educational and the research arenas. 


\section{Institution(s) \\ University of Wisconsin School of Medicine and Public Health/ William S. Middleton Veterans Hospital}

Program Type: Fellowship in Women's Health

Date Established: May 1995

Number of Positions: 1-2 per year

Duration of Program: 2-3 years

Sponsored by:

University of Wisconsin Center for Women's Health Research

Women's Veterans Health Program

Co-Sponsoring Institution(s)/Department(s): $\mathrm{OB} / \mathrm{GYN}$

\section{Contact(s):}

Molly Carnes, MD, MS

Program Director

Professor of Medicine, Psychiatry, and Industrial \& Systems Engineering

University of Wisconsin Center for Women's Health Research

Cynthia Phelan, PhD, RN

Associate Director

Scientist

700 Regent Street, Suite 301

Madison, WI 53715

Telephone: (608) 263-9770

Fax: (608) 265-6423

E-mail: mlcarnes@wisc.edu

Website: http://www.womenshealth

.wisc.edu/Home/Programs/TrainingAnd

CareerDevelopmentPrograms.aspx
Departments of Medicine, Psychiatry, and

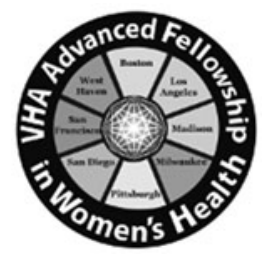

\section{Eligibility Requirement(s)}

Physicians must be board certified or board eligible in Internal Medicine, Psychiatry, or Obstetrics \& Gynecology; non-physician clinical postdoctoral fellows may hold doctoral degrees in Psychology, Nursing, Speech Language Pathology, or Pharmacy.

\section{Required Activities}

Weekly multidisciplinary clinic, course on women and leadership, monthly administrative and research conference, and mentored research.

\section{Elective Activities}

A full spectrum of supplemental clinical, didactic, basic or applied research activities are available.

\section{Special Degree(s)/Certificate(s) Offered}

Most physician fellows enroll in a graduate degree program: usually the MS program in Population Health, Clinical Investigation, or Education. Non-physician fellows do not need to complete additional coursework.

\section{Goals of the Program}

To train future leaders in academic health sciences who will be engaged in research teaching, and program development that will improve the health of women. Each fellow completes an individualized career development plan (ICDP) around 6 core areas essential to a successful research-based academic career: research excellence in a chosen area, study design and statistics, leadership/management, scientific writing, oral presentation to a variety of audiences, and responsible conduct of research. The ICDP serves as a roadmap for activities and learning objectives to be accomplished during the AFWH.

\section{Reason for Initiating Program}

Women leaders in academic science and medicine are integrally related to advancements in the health of women. This program is one of 8 Advanced Fellowships in Women's Health (AFWH) funded by the Veterans Health Administration. Additionally, the Madison VA is the Hub site for the program which seeks to establish a community of practice for fellows and program directors of these programs. 
Institution(s)

VA Connecticut Healthcare System/Yale School of Medicine

Program Type: Advanced Fellowship in Women's Health

Date Established: 2012

Number of Positions: 2 per year

Duration of Program: 2 years

Sponsored by:

VA Connecticut Healthcare System

Yale School of Medicine

Contacts:

Program Director: Sally G. Haskell, MD

Deputy Chief Consultant and Director

Comprehensive Women's Health

Women's Health Services, Patient Care Services

VA Central Office

Associate Professor, Yale School of Medicine

VA Connecticut Healthcare System

950 Campbell Avenue, West Haven CT 06516

Telephone: 203-932-5711 x5546

Fax: 203-937-4935

Email: Sally.Haskell@va.gov

Co-Director: Cynthia Brandt, MD MPH

Advanced Fellowship in Women's Health

Staff Physician VA Connecticut

Co-Director VA Special Informatics Fellowship

Professor, Yale School of Medicine

VA Connecticut Healthcare System

950 Campbell Avenue, West Haven CT 06516

Telephone: 203-932-5711 x5546

Fax: 203-937-4935

E-mail: Cynthia.Brandt@va.gov

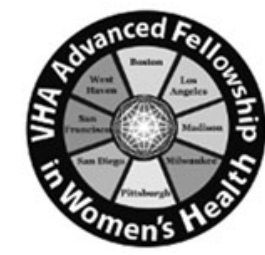

\section{Eligibility Requirement(s)}

Eligible physicians must have graduated from an Accreditation Council for Graduate Medical Education (ACGME) accredited residency; be board certified or board eligible in internal medicine (or one of its subspecialties), family practice, gynecology, psychiatry, or surgery; and have an active, unrestricted U.S. medical license. They must desire to lead women veterans' healthcare in the 21 st century. International medical graduates must also have a current visa to participate in the program and an Educational Commission for Foreign Medical Graduates (ECFMG) certificate that is valid indefinitely. Applicants with a J-1 visa must have current ECFMG sponsorship to participate in the program.

Eligible postdoctoral associated health professionals must be a US citizen, demonstrate interest in pursuing a VA career with women's health as a significant focus, be qualified in a health profession relevant to the health of women veterans (nurses, psychologists, and others), not be simultaneously enrolled in an accredited clinical training program, demonstrate interest in pursuing VA career with women's health as a significant focus and meet the education and licensure requirements listed in the program announcement.

\section{Required Program Activities}

The Advanced Fellowship for Women's Health provides two years of post residency, post-doctoral research, education, and clinical learning opportunities to eligible physicians and associated health professionals. Fellows spend approximately 75 percent of their time in research and education and 25 percent in clinical care at the VA Connecticut Healthcare System site. Mentors of national stature provide guidance to fellows in rich learning environments. Graduates are expected to be role models in leading, developing, conducting, and evaluating innovative research, education, and clinical care in health issues pertaining to women veterans.

\section{Special Degree(s)/Certificate(s) Offered}

Fellows participate in research training curriculum at Yale University, and eligible candidates may have an opportunity to receive a Master of Health Sciences.

\section{Goals of the Program}

Develop women's health scholars who understand and are responsive to issues central to women Veteran healthcare in clinical, policy and research settings. To provide an outstanding training program that will contribute to the improvement of clinical practice by educating Comprehensive Women's Health Clinicians who are truly expert in the care of women veterans who will also be able to contribute to the scholarly pursuit of women's health research and policy development.

\section{Other Program Features}

The fellowship site research foci include: Gender disparities in cost, utilization and medical and mental health outcomes after combat exposure in Iraq and Afghanistan (The Women Veterans Cohort Study); medical informatics; chronic pain in women veterans; gender disparities in cardiovascular risk and outcomes; implementation of comprehensive women's health in the Veterans Health Administration. 
VA Connecticut has a Comprehensive Women's Clinic that provides primary care to women veterans with co-located Gynecology and Mental Health Services where:

- Fellows participate in clinical activities within the women's health clinic that include opportunities for teaching and direct patient care.

- Fellows may also arrange other clinical experiences relevant to their interests and disciplines.

Education, training and health policy opportunities include:

- Research training curriculum at Yale University and eligible candidates may have an opportunity to receive a Master of Health Sciences.

- Participation in health policy or quality related projects through VA Central Office of Women's Health Services

\section{Reason for Initiating Program}

In 1994, the Office of Academic Affiliations (OAA) started VA's Advanced Fellowships Program in Women's Health to better serve female veterans. There was a growing awareness of the complex health needs of women veterans and the importance of training physicians for academic careers in this specialized field. In 2012, after a competitive review, OAA selected VA Connecticut Healthcare System as a fellowship site based on the medical facility's ability to provide the needed population of women veterans, the strength of its academic program, its ability to provide expert research mentoring, and its commitment to leadership in women veterans health issues. 
Institution(s)

VA San Diego Healthcare System (VASDHS) and University of California, San Diego

Date Established: 2012

Number of Positions: 2 per year (One psychology fellow and one internal medicine fellow)

Duration of Program: 2 years

Sponsoring Institutions or Departments:

Departments of Psychology and Internal Medicine at VASDHS

Co-sponsoring Institutions or Departments: Departments of Psychiatry, Internal Medicine, and Surgery at UCSD

Program Directors:

Carolyn Allard, $\mathrm{PhD}$

Co-Director, Clinical Psychology Track

Program Director, Military Sexual Trauma (MST) \& Interpersonal Trauma (IPT)

Associate Professor of Psychiatry, School of Medicine, UCSD VASDHS, Mission Valley OPC (116A4Z) 8810 Rio San Diego Dr, San Diego CA 92108 Telephone: 619-400-5189

Fax: 619-400-5171

E-mail: callard@vapop.ucsd.edu

Robin Moyer, MD, MBA

Co-Director, Internal Medicine Track

Medical Director, Women's Health VASDHS

Associate Professor of Medicine,

School of Medicine, UCSD

VASDHS, Mission Valley CBOC $118 \mathrm{z}$

8810 Rio San Diego Dr, San Diego CA 92108

Telephone: 619-400-5101

Fax: 619-400-5055

E-mail: robin.moyer@va.gov

topics relevant to the fellows' individualized training plan.

Leadership (10\%):

Fellows will be trained in and expected to contribute to program administration through participation on the Women's Health Committee, local outreach and performance improvement activities and dissemination of women's health information to staff and trainees through in-service seminars.

\section{Goals of the Program:}

The overall goal of the Advanced Fellowship in Women's Health is to provide interdisciplinary training to postdoctoral fellows to prepare them for careers as independent women's healthcare specialists. Through a combination of clinical, research, and teaching experiences, cross-disciplinary training opportunities, and supervision from women's health specialists, we aim to cultivate leaders in women's health.

\section{Reason for Initiation:}

This fellowship was initiated to better serve the growing population of female veterans with unique needs for which there is insufficient understanding of optimal provision of health services. 